\title{
ASPECTOS REGIONALES DE LA EXPANSIÓN DE LA EDUCACIÓN SUPERIOR EN MÉXICO, 1959-1967
}

\author{
AdRIán Lajous Vargas * \\ El Colegio de México
}

\begin{abstract}
UNA DE LAS características de la expansión de la población escolar en las instituciones de educación superior en México, ${ }^{1}$ y de los resultados numéricos de la misma, ha sido su desequilibrio regional. Existe una considerable concentración en el Distrito Federal. Sin embargo, en el período 1959-1967 se advierte una tendencia contraria, y, en el interior de algunas regiones, también una menor concentración (aunque no en las dos principales). El propósito de estas páginas es examinar estas tendencias, dentro de las magnitudes globales de la educación superior en México, a fin de permitir evaluar su significado.
\end{abstract}

\section{LAS CIFRAS GLOBALES}

Conviene examinar primero algunas de las principales cifras globales relativas a la educación superior. De 1959 a 1967 la población escolar que cursaba estudios profesionales (licenciatura o su equivalente) en instituciones de educación superior pasó de 69.330 a 144937 estudiantes (véanse el cuadro A-1 y la gráfica 1). ${ }^{2}$ Esta duplicación en el número de alumnos se realizó a una tasa media de crecimiento anual de $9.7 \%$. El crecimiento se efectuó a un ritmo más acelerado en la primera mitad del período estudiado: entre 1959 y 1963 acusó una tasa media de $10.5 \%$ y en el período $1963-1967$ de $8.9 \%$.

La desaceleración en el ritmo de crecimiento se debió a que la Universidad Nacional Autónoma de México estabilizó su población escolar a los niveles de 1962 (véase el cuadro A-2), por lo que el Distrito Federal en su conjunto creció más lentamente. Ello no pudo ser compensado por el rápido aumento de la inscripción en instituciones del

* El presente artículo es un extracto de la tesis profesional del autor, titulado Aspectos de la educación superior y el empleo de profesionistas en México, 19591967, presentada a la Escuela Nacional de Economía, Universidad Nacional Autónoma de México, 1967, para obtener la licenciatura en Economía. El autor agradece a los licenciados Alfonso Rangel Guerra y Enrique Romero, de la Asociación Nacional de Universidades e Institutos de Enseñanza Superior, así como a la señora Clara J. de Bialostozky, y, muy especialmente, al licenciado Pedro Uribe Jr., de El Colegio de México, la cooperación que le prestaron en varios aspectos del análisis.

1 Véase en el apéndice (pp. 419-421) la definición que se da en este trabajo a "educación superior", para los efectos de la estadística presentada.

2 Los cuadros numerados A-1, A-2, etc., aparecen incluidos en el apéndice a este trabajo (pp. 422427). 
resto del país. Como consecuencia, puede afirmarse que este cambio en el ritmo de crecimiento se debió a la limitación de la oferta de plazas y no a una menor expansión de la demanda de lugares en instituciones de educación superior, a pesar de que aún no es posible determinar cuál fue el efecto sobre la demanda al agregar la Universidad Nacional un grado más al ciclo preparatorio.

La magnitud y la tendencia del crecimiento de la población escolar en provincia fueron diferentes a las experimentadas en el Distrito Federal. En el período 1959-1967, la matrícula en instituciones de educación superior del interior creció al $15.8 \%$ anualmente, mientras que la del Distrito Federal logró sólo una tasa del $6.3 \%$. Mientras que en la provincia se dio un crecimiento más rápido en la segunda mitad del período estudiado, en el Distrito Federal se presentó el caso opuesto.

La tasa de crecimiento de la inscripción fue mucho mayor que la de la población en edad de asistir a la universidad, lo cual permitió un aumento rápido de la tasa de escolaridad. En 1959, el número de estudiantes en instituciones de educación superior equivalía al $2.4 \%$ de la población del grupo de edad de 20 a 24 años. Este coeficiente de participación se elevó a $3.84 \%$ en 1967, por lo que la tasa de escolaridad creció a un ritmo de $6.1 \%$ anualmente (véanse los cuadros A-3, A-4 y la gráfica 2). Aun así, el crecimiento demográfico absorbió el $28.3 \%$ de la expansión de los servicios educativos de nivel superior. Es importante señalar que en el futuro el esfuerzo educativo tendrá que ser mayor si se quieren seguir aumentando las tasas de escolaridad a un ritmo semejante al de los últimos años. La presión demográfica representada por este grupo de edad será aun más fuerte en los próximos años. Se puede estimar que el número de jóvenes entre 20 y 24 años de edad crecerá a un ritmo del $4 \%$ en el período 19651970 y al $4.25 \%$ entre 1970 y $1975 .{ }^{3}$

El sistema de educación superior produjo 8400 egresados en 1960 y se estima que en 1967 éstos ascenderían a 18553 . (Véanse el cuadro A-5 y la gráfica 1.) El número de egresados en el Distrito Federal aumentó de 5720 a 10458 ; en el resto del país, de 2680 a 8095 , con lo que la proporción de estos últimos se elevó de $31.9 \%$ a $43.4 \%$ (véase el cuadro A-6). El Distrito Federal, en términos generales, acusa una proporción menor que los estados en cuanto a egresados de las carreras tradicionales.

El incremento nacional del total de egresados fue de $120.9 \%$, a una tasa media del $12 \%$. Debido a que esta tasa fue superior a la experimentada por la población escolar, la participación de los egresados en ésta se elevó de 10.9 a $12.8 \%$, lo que implicó una estructura por grado ligeramente más madura. No existe gran diferencia, desde el punto de vista de la madurez estructural, entre la provincia y el Distrito Federal. En la primera este coeficiente es de $12 \%$ en 1967, mientras que el del Distrito Federal es de $13.5 \%$.

Durante el periodo de estudio se llevaron a cabo cambios importantes en la distribución por carrera de la población escolar. Las profesiones tradicionales - derecho, medicina e ingeniería civil- perdie-

3 Con base en Raúl Benítez Zenteno y Gustavo Cabrera A., Proyecciones de la población de México, 1960-1980, México, Banco de México, 1966. 


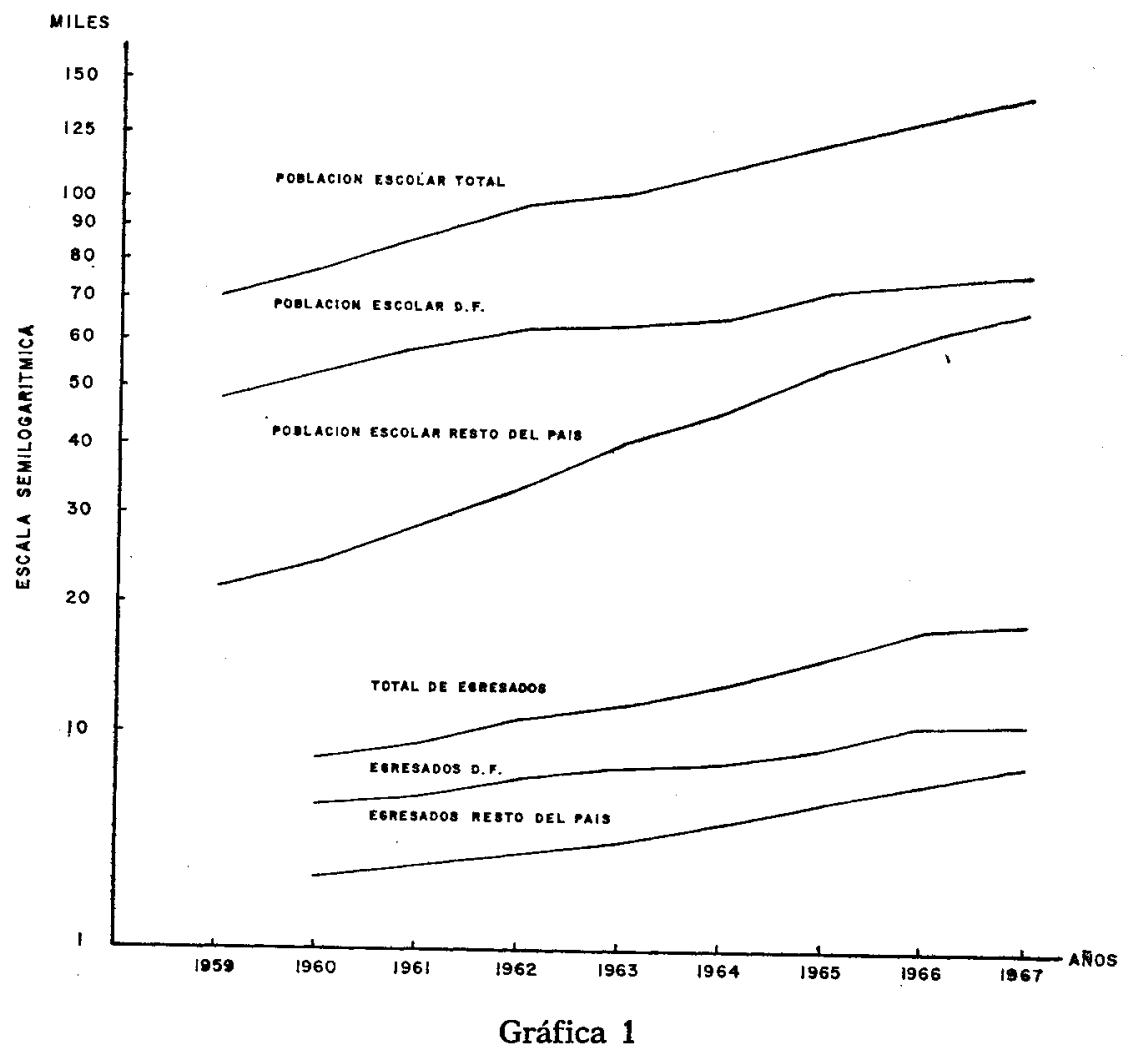

México: Población escolar y NúMERo dE EGResados DE INSTItuciones DE EDUCACIÓN SUPERIOR, 1959-1967 


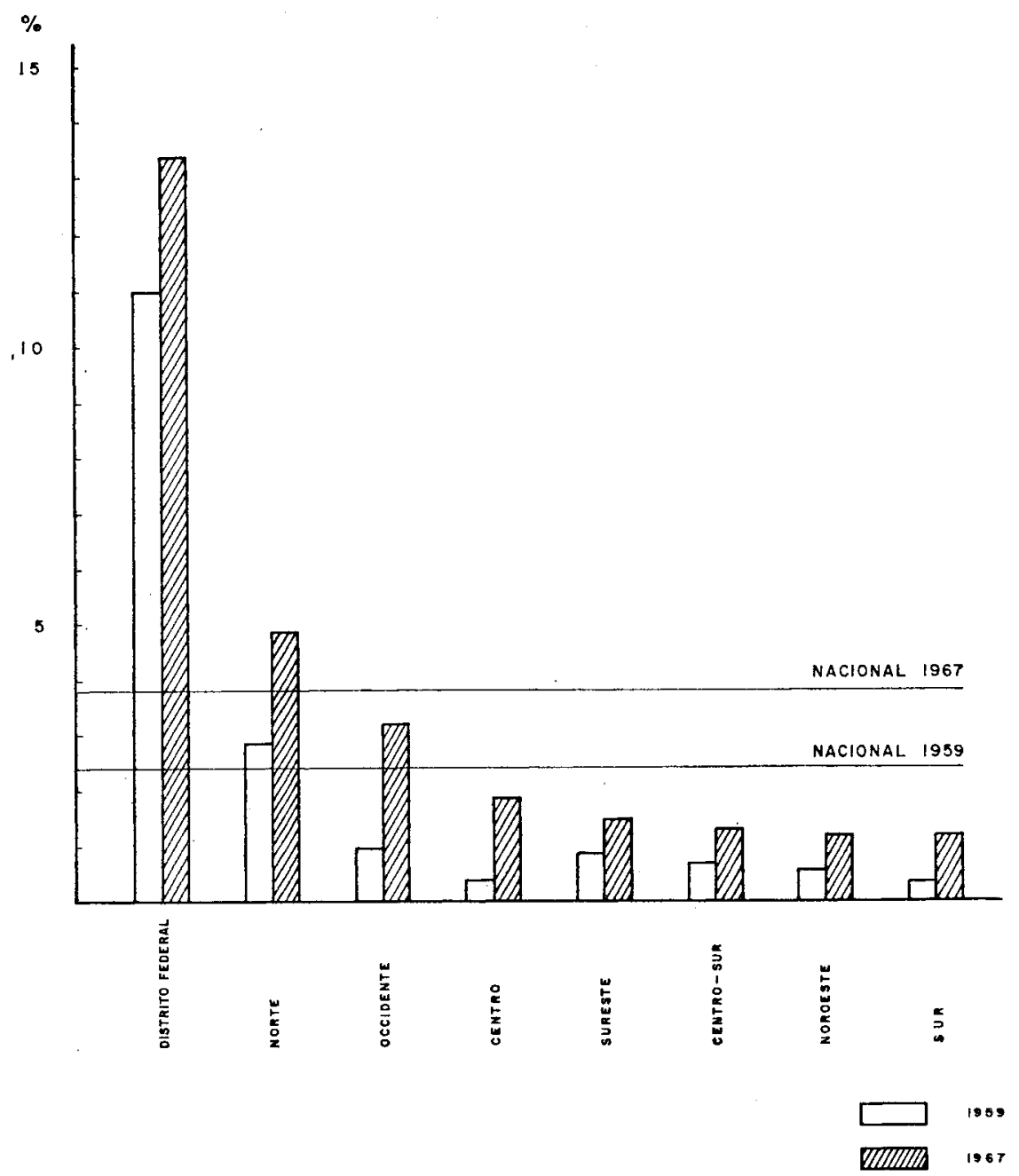

Gráfica 2

México: Partictpactón de la poblactón universitaria en la poblactón DE 20 A 24 AÑOS, POR REGIONES, 1959 Y 1967 
ron importancia relativa dentro del sistema de educación superior (véanse los cuadros A-1, A-5 y A-6 y la gráfica 3). Estos cambios se realizaron en forma más significativa en el Distrito Federal que en el interior, en donde siguieron la misma tendencia pero a un ritmo más lento. En términos generales, la distribución por carreras se hizo más favorable a aquellas que tienen mayor importancia directa en el crecimiento económico. Aunque algunas de estas ramas profesionales disminuyeron su participación relativa en la población escolar total, al considerarlas en su conjunto puede observarse un incremento. Es al desagregar por carrera a cada rama profesional cuando mejor se aprecia la modernización de la estructura.

\section{DISTRIBUCIÓN POR CARRERAS}

La concentración de la población escolar en unas cuantas instituciones es aún muy alta. En 1959, cinco universidades - la Universidad Nacional, el Instituto Politécnico Nacional y las de Guadalajara, Nuevo León y Puebla - absorbían casi las tres cuartas partes de la población escolar total. En 1967, estas universidades tenían matriculado el $56.6 \%$ de los estudiantes del país.' (Véase el cuadro A-2.)

A nivel nacional, las ciencias administrativas -incluyen derecho, economía, ciencias políticas y sociales, contabilidad y administración de empresas- crecieron en forma acelerada durante el período 19591967. Los componentes de esta rama profesional acusaron una expansión diferencial que implicó un cambio significativo en su estructura (véase el cuadro A-1). La población escolar se incrementó en un $250 \%$, a una tasa media de $12.5 \%$. Todas las carreras, exceptuando derecho, crecieron más rápidamente que el total de la rama. En la segunda mitad del período estudiado, la expansión se realizó a un ritmo más lento -al $10.0 \%$ anualmente- mientras que en la primera mitad se observó una tasa media de $15.1 \%$. Para 1967, todas las carreras de esta rama - menos derecho- absorbian una mayor proporción de la población escolar universitaria. En derecho, aunque el número total de estudiantes seguía creciendo en términos absolutos, en el Distrito Federal empezó a disminuir a partir de 1965.

En el cuadro A-5 puede observarse la evolución del número de egresados de ciencias administrativas (véase también la gráfica 4). Administración de empresas no logró sobrepasar el número de egresados de la carrera de economía a pesar de que ya lo había hecho en lo que se refiere a población escolar en 1965. Ello se debe a que esta carrera se expandió en épocas más recientes, por lo que no egresan aún los estudiantes que explican esa expansión. La disminución en el número de egresados en ciencias políticas y sociales se debió a que aumentó un año a los programas de estudios de dichas carreras.

La población escolar y el número de egresados en ciencias naturales y exactas se cuadriplicaron en el período de estudio. El esfuerzo desarrollado en esta rama, especialmente en las carreras físico-matemáticas, fue muy grande aunque hay que tomar en cuenta que se partió de una base muy reducida. La importancia de este crecimiento radica en el verdadero "despegue" que lograron estas carreras (véanse los cuadros A-1, A-5 y A-6, y las gráficas 3 y 4). 


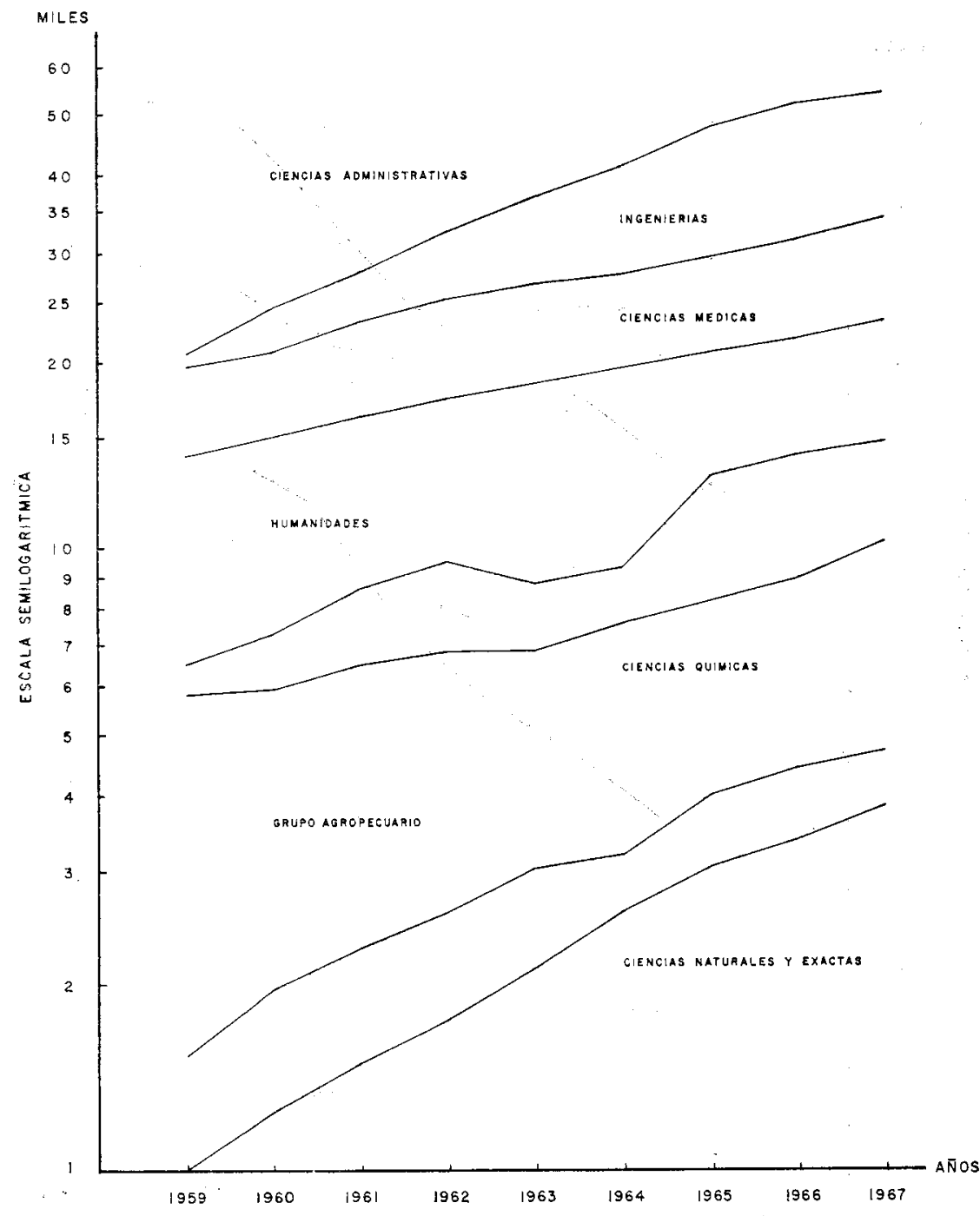

Gráfica 3

Méxtco: Poblactón escolar en instituciones de educación superior, POR RAMA PROFESIONAL, 1959-1967 


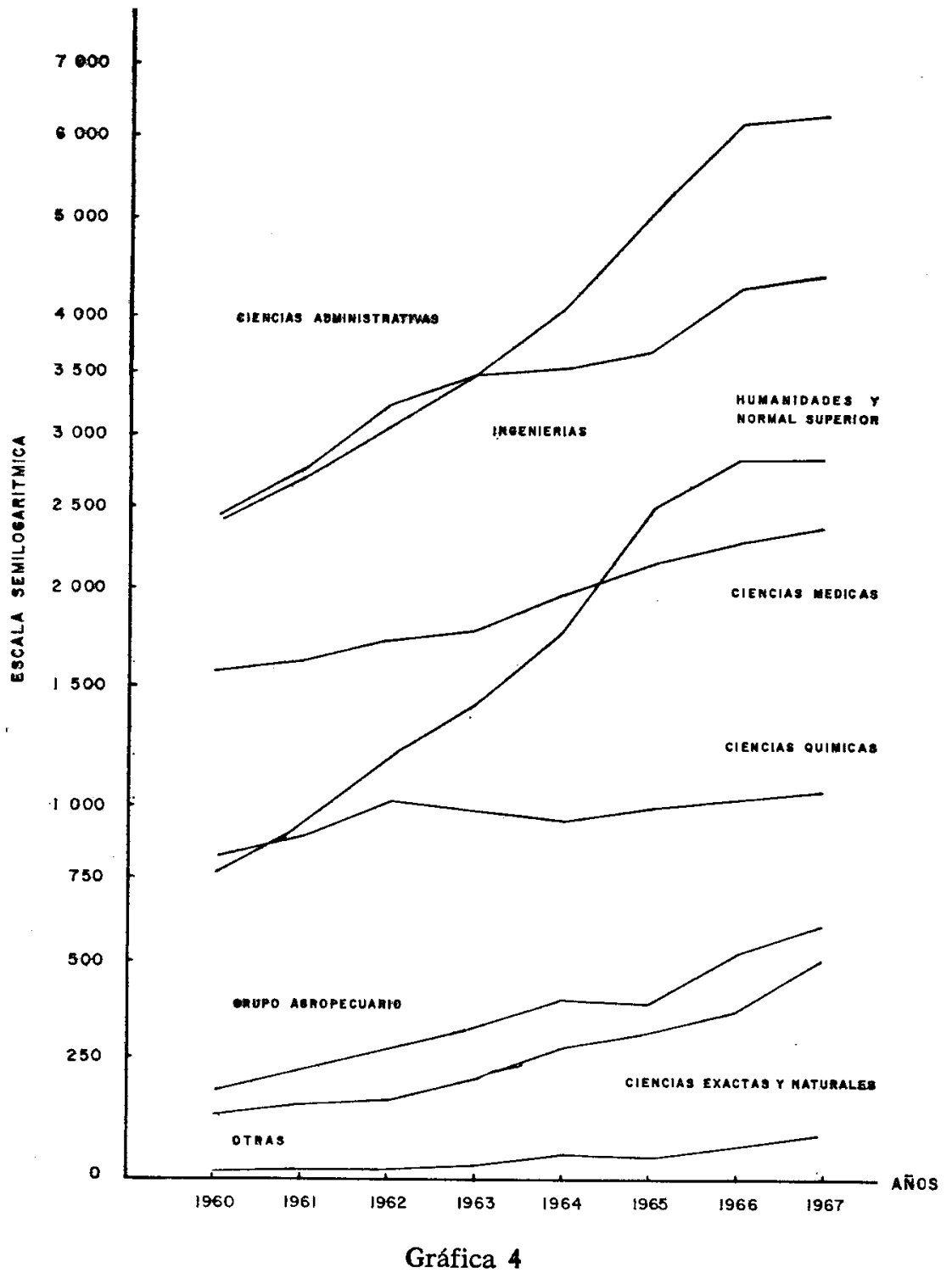

MÉxICO: NúMERo DE EGRESADOS DE INSTITUCIONES DE EDUCACIÓN SUPERIOR, POR RAMAS PROFESIONALES, 1960-1967 
De las ciencias químicas, sólo la ingeniería química y "otras carreras" de esta rama profesional -incluye a las carreras más modernas y especializadas - crecieron en forma significativa, sobre todo en la segunda mitad del período 1959-1967. El número de egresados se mantuvo relativamente estable. No se refleja aún el crecimiento reciente de la población escolar en las carreras que lograron expandirse. El descenso del número de egresados de algunas de estas carreras se debió principalmente a que muchas escuelas profesionales aumentaron los años de estudios necesarios para cubrir los programas.

Aunque la población escolar en la rama de ingeniería creció en su conjunto a un ritmo más lento que la población escolar total, algunas de las ingenierías observaron un crecimiento mayor. La ingeniería mecánica y eléctrica creció al $11.0 \%$ anualmente entre 1959 y 1967 y la ingeniería industrial logró una tasa de $35 \%$. Esta carrera fue absorbida casi en su totalidad por los institutos tecnológicos regionales de reciente creación. Las carreras más antiguas de esta rama crecieron lentamente en relación con la población escolar total.

La población escolar en las carreras de veterinaria e ingeniero agrónomo se triplicó entre 1959 y 1967. La tendencia del número de egresados de agronomía resulta errática. Es casi seguro que se deba a un error de información, pues no parece haber otra explicación. Es importante señalar que la carrera de agronomia se localiza en su totalidad en la provincia. Este sesgo resulta de que la Escuela Nacional de Agricultura está ubicada en el estado de México. En la práctica puede considerársele como una escuela profesional de la ciudad de México debido a la corta distancia a que se encuentra de ésta.

La evolución de la población escolar de la carrera de medicina resultó en un ritmo relativamente lento. Entre las posibles explicaciones de este fenómeno parecen sobresalir dos. La primera de ellas es el malestar profesional que padece esta carrera debido a las fricciones producidas al pasar de ser una profesión eminentemente liberal a una socializada. Ello se encuentra reflejado, en parte, en la emigración a un nivel significativo de médicos mexicanos a los Estados Unidos. La segunda es el proceso de redistribución de la población escolar al madurar la estructura profesional del sistema de educación superior, lo que hace disminuir en términos relativos la importancia de las carreras tradicionales.

\section{LAS DIFERENCIAS POR REGIONES}

Myers ha señalado la importancia que revisten los desequilibrios regionales en la formación de recursos humanos en México. La magnitud de dichos desequilibrios hace que el uso de agregados nacionales sea poco adecuado para el análisis y la planeación de estos recursos. Ellos sólo representan un promedio de niveles regionales muy diversos. ${ }^{4}$ Es de especial importancia para el estudio de la educación superior el hecho de que estos desequilibrios cobren mayores dimensiones conforme se avanza en el sistema educativo. El grado de concen-

1 Charles N. Myers, Education and National Development in Mexico. Princeton, Industrial Relations Section, Princeton University, 1965. 
tración geográfica de la población con diferentes niveles de educación se relaciona directamente con el nivel educativo alcanzado.

La magnitud de las diferencias regionales del acervo de población instruida puede verse claramente al comparar las entidades que se encuentran en los niveles extremos de la escala. En 1960, el $21.7 \%$ de la población en el Distrito Federal de seis o más años de edad no había terminado un solo año de educación formal. En el estado de Guerrero dicha proporción fue el $70.8 \%$. En este mismo estado sólo el $5.5 \%$ de la población de 12 ó más años de edad había terminado la escuela primaria, mientras que en el Distrito Federal el $46.7 \%$ lo había hecho. Treinta y cuatro de cada mil personas de 23 o más años de edad había completado sus estudios superiores en el Distrito Federal y en Guerrero sólo 2 de cada mil personas. En términos generales, los estados cercanos a la frontera norte del país eran los que más se acercaban a este respecto a la ciudad de México. ${ }^{5}$

Al utilizar el indicador compuesto de desarrollo de recursos humanos de Harbison y Myers, ${ }^{6}$ que mide principalmente la capacidad para formar recursos humanos de alto nivel, Charles $\mathrm{N}$. Myers estimó que México se encuentra clasificado en un alto rango dentro del grupo de "países parcialmente desarrollados" (grupo II). Ello significa que ocupa un lugar entre países como Paquistán, Jamaica, Turquía y Ecuador. Si se toman en cuenta diversas entidades del país, se puede ver que el índice del Distrito Federal está entre el de la Unión Soviética y el de Canadá, mientras que el de Oaxaca se encontraría entre los indices de Liberia y Kenia. Lo anterior parece indicar que existe una menor brecha en la capacidad para formar mano de obra de alto nivel entre los Estados Unidos y el Distrito Federal que entre éste y el estado de Oaxaca. En 1960, el nivel educativo modal alcanzado por la población de 30 o más años de edad en el Distrito Federal fue de tres años, en tanto que en todas las demás entidades del país fue cero. ${ }^{7}$

En el cuadro A-4 y en la gráfica 2 pueden observarse las diferencias en los coeficientes de participación de la población escolar de nivel superior en la población de 20 a 24 años entre estados y regiones. En 1967, sólo el Distrito Federal y la región Norte (Coahuila, Nuevo León y Tamaulipas) aparecen con un coeficiente superior al nacional, que es de $3.8 \%$. Si se desagrega por estados, el Distrito Federal (13.4\%), Nuevo León. $(9.27 \%)$ y Jalisco $(5.0 \%)$ lograron un nivel mayor que el promedio nacional..$^{\mathrm{s}}$

El cuadro A-4 muestra también el esfuerzo realizado por las diferentes regiones en el período 1959-67. Las diferencias en términos absolutos de las tasas de escolaridad en el nivel superior entre las ocho regiones que componen el país aumentaron respecto a la media nacional. En 1959, la desviación media de los coeficientes de participación de la población escolar universitaria en la población de 20 a 24 años de edad fue de $2.65 \%$ y en 1967 de $3.68 \%$. La dispersión relativa de

5 Dirección General de Estadística, VIII Censo General de Población, 1960.

6 F. Harbison y C. A. Myers, Education, Manpower and Economic Growth: Strategies of Human Resource Development. Nueva York, McGraw-Hill, 1963, p. 31.

7 Charles N. Myers, op. cit., pp. 29-31.

8 La regionalización utilizada es la de la Asociación Nacional de Universidades e Institutos de Enseñanza Superior. Véase la composición de las regiones en el cuadro A-2 del apéndice estadístico. 
los coeficientes de las diversas regiones respecto a la media nacional disminuyó de $104 \%$ a $95 \%$.

No parece existir una relación muy estrecha entre el nivel de desarrollo de las entidades del país y la tasa de escolaridad en los niveles superiores. Esta relación sólo es clara en las entidades más ricas y en las muy pobres. Es más importante en la explicación de los diferentes niveles de escolaridad la existencia de grandes concentraciones urbanas, pues es en éstas donde se establecen las universidades. Es importante también la cercanía a otros centros universitarios de importancia, como sucede en los estados colindantes con Nuevo León y el Distrito Federal.

\section{CONCENTRACIÓN DE LA EDUCACIÓN SUPERIOR ${ }^{9}$}

Los grandes desequilibrios regionales de población escolar implican una concentración geográfica de la misma. Este fenómeno es una de las características más sobresalientes del sistema de educación superior de México, así como la concentración de estudiantes en unas cuantas carreras. El propósito del análisis que se realiza a continuación es el estudio de la concentración geográfica de la población estudiantil al nivel de estados y regiones; en segundo lugar, se trata de analizar, por separado, su concentración por carrera; y en tercero, se intenta relacionar los dos fenómenos e investigar su dependencia mutua.

La concentración de servicios educativos es un concepto semejante al de la concentración del ingreso o de la población. Se dice, por ejemplo, que el ingreso de la comunidad no está concentrado si su distribución es uniforme. La concentración de la población en un cierto número de entidades geográficas es cero si la densidad de población es la misma en todas ellas.

En lo anterior se presenta una idea a priori de cómo debe distribuirse el ingreso o la población para que no exista concentración. La idea a priori de distribución, de la que se parte para medir la concentración geográfica de los estudiantes de nivel superior, es la siguiente: la población de estudiantes universitarios debe repartirse en los estados en forma proporcional a la población del grupo de edad de 20 a 24 años. En la concentración por carrera, la idea a priori es la de una distribución uniforme: la concentración cero se da cuando todas las carreras tienen el mismo número de estudiantes.

Las medidas de concentración utilizadas han sido propuestas recientemente por Uribe para el estudio de la concentración de la población por área geográfica y por tamaño de localidad habitada. La concentración se mide, en todos los casos, por la cantidad de información "añadida" (en el sentido de la teoría de la información) al conocimiento de la distribución a priori por el conocimiento de la distribución observada (a posteriori). Por medio de esto se logran propiedades ana-

9 La información de esta sección fue procesada por CEIR de México, S. A. en su computadora GE415. Se utilizó el programa empleado por Pedro Uribe Jr. en su trabajo "Concentración demográfica y estructura urbana: un enfoque vía teoría de la información", DEMOGRAFf́ Y ECONOMf́a, Vol. 1, Núm. 2, 1967. Esta sección del trabajo intenta aplicar la metodología de la investigación antes mencionada a la concentración escolar. 
líticas útiles. ${ }^{10}$ La concentración geográfica total es la suma de dos términos: la de la población escolar entre las regiones y una media ponderada de concentraciones internas de las regiones. La concentración interregional es la discrepancia entre la distribución regional de los estudiantes y la distribución regional de la población de 20 a 24 años de edad. La concentración intrarregional resulta de la diferencia entre la distribución de la población escolar en los estados de la región y la distribución correspondiente de la población de 20 a 24 años.

Desde el punto de vista de cómputo, la concentración intrarregional puede obtenerse como el logaritmo de un cociente cuyo numerador es la media geométrica de las densidades de estudiantes por habitante de 20 a 24 años de edad en cada región y cuyo denominador es la misma densidad a nivel nacional. Si las densidades aludidas son iguales en todas las regiones del país, el cociente es la unidad y su logaritmo es cero. El valor numérico de la concentración interregional depende de la base que se escoja para los logaritmos. Lo común en la teoría de la información es utilizar logaritmos de base 2, por lo que las unidades en que se expresa la información se llaman bits (binary information unit).

En el caso de las concentraciones internas de las regiones, el cómputo es exactamente el mismo: las densidades regionales se sustituyen por las densidades de los estados que componen la región. En el denominador del quebrado, la densidad del país se sustituye por la de la región correspondiente. Se trata de medias geométricas ponderadas con población escolar.

Se procesó la información de la población escolar de 1959 y 1967. Los resultados se encuentran resumidos en los cuadros 1 y 2 . El cuadro 1 contiene los valores, en bits, de la concentración total, la concentración interregional y la concentración intrarregional; así como sus valores relativos (concentración total igual a 100 por ciento).

\section{Cuadro 1}

México: Concentración geográfica de la población escolar, 1959 y 1967 (en bits y porcientos)

\begin{tabular}{lccc}
\hline & 1959 & 1967 & Media \\
\hline Concentración total & 1.3231 & 0.7970 & 1.0601 \\
& $(100.00)$ & $(100.00)$ & $(100.00)$ \\
Concentración interregional & 1.1581 & 0.6620 & 0.9101 \\
& $(87.53)$ & $(83.06)$ & $(85.85)$ \\
Concentración intrarregional & 0.1650 & 0.1350 & 0.1500 \\
& $(12.47)$ & $(16.94)$ & $(14.15)$ \\
\hline
\end{tabular}

Nota: Las unidades en porcientos están entre paréntesis.

Se advierte que la parte más importante de la concentración está dada por las diferencias regionales, las cuales representan, en promedio, el $86 \%$ de la concentración geográfica. El descenso observado

10 Uribe, loc. cit. 
entre 1959 y 1967 puede ser atribuido casi en su totalidad a la concentración interregional.

La estructura interna de las regiones, en promedio, cambió muy poco. Las regiones que se desconcentraron tenían una población relativamente pequeña, por lo que no lograron contribuir en forma significativa al proceso global (véase el cuadro 2).

\section{Cuadro 2}

MÉxico: CONCENTRACIONES INTERNAS DE LAS REGIONES Y SUS CONTRIBUCIONES A LA CONCENTRACIÓN INTRARREGIONAL, 1959 Y 1967

(en bits y porcientos respectivamente)

\begin{tabular}{lcc}
\hline \multicolumn{1}{c}{ Región } & 1959 & 1967 \\
\hline Noroeste & 0.3237 & 0.0682 \\
Norte & $(4.89)$ & $(1.77)$ \\
& 0.8443 & 0.3617 \\
Centro & $(48.34)$ & $(30.72)$ \\
& 0.5247 & 0.1462 \\
Occidente & $(5.18)$ & $(4.32)$ \\
Centro-sur & 0.2279 & 0.2419 \\
Sur & $(10.46)$ & $(26.98)$ \\
Sureste & 0.6159 & 0.3813 \\
Distrito Federal & $(19.60)$ & $(18.18)$ \\
& 0.6102 & 0.4351 \\
& $(10.30)$ & $(16.75)$ \\
& 0.2328 & 0.1844 \\
& $(1.23)$ & $(1.24)$ \\
& 0.0000 & 0.0000 \\
& $(0.00)$ & $(0.00)$ \\
\hline
\end{tabular}

La contribución de una región se mide como el producto de la concentración interna por su proporción de población escolar y se expresa como porciento de la concentración intrarregional total. Por ejemplo, en la región noroeste hubo una desconcentración significativa en términos absolutos. Como su participación en la población escolar es muy pequeña ( $2.5 \%$ en 1959 y $3.5 \%$ en 1967) el impacto sobre la desconcentración intrarregional fue reducido. El ligero descenso observado en la concentración intrarregional puede explicarse, casi en su totalidad, en términos de la desconcentración interna de la región norte (expansión de las universidades de Tamaulipas y Coahuila).

Se ha mencionado ya que la concentración por carrera se considera igual a cero cuando cada carrera absorbe el mismo número de estudiantes. Su obtención es idéntica a la de la concentración geográfica: la distribución a posteriori es la observada y la a priori es uniforme. Se trata, pues, del logaritmo de un cociente cuyo numerador es la media geométrica del número de estudiantes en cada carrera y cuyo denominador es el número de estudiantes entre el número de carreras. La concentración de la población escolar por carrera en México fue de 0.8364 bits en 1959 y de 0.6564 bits en 1967. Ello significó una dismi- 
nución del $21.5 \%$ mientras que la desconcentración geográfica total, que pasó de 1.3231 bits en 1959 a 0.7970 en 1967, fue de un $40 \%$.

Es importante estudiar conjuntamente los fenómenos de concentración geográfica y por carrera de la población escolar. El punto de partida de este análisis es la distribución conjunta de los estudiantes por estados y por carreras. Lo tratado hasta aquí corresponde al estudio de la concentración de las distribuciones marginales que corresponden a la distribución conjunta aludida.

Para cada carrera es posible calcular su concentración geográfica. Se puede así hablar de la concentración geográfica de los estudiantes de economía, de derecho o de ingeniería. Cada una de estas concentraciones tiene un componente interregional y otro intrarregional. $\mathrm{La}$ concentración geográfica marginal obtenida anteriormente es menor que la media de las concentraciones por carreras. La diferencia radica en lo que puede llamarse, siguiendo una terminología semejante a la utilizada por Uribe, la heterogeneidad de la composición profesional de los estados. ${ }^{11}$

Al nivel nacional, la concentración media queda expresada como concentración geográfica marginal más heterogeneidad de la composición profesional: se trata de "información" ganada si la distribución a priori de las profesiones, para cada estado, es igual a la del país y la a posteriori es la observada. Si la distribución a posteriori es igual a la distribución a priori, la cantidad de estudiantes es independiente

\section{Cuadro 3}

MÉXICO: Descomposición dE LA CONCENTRACión GEOGRÁFICA MEDIa dE LAS DIVERSAS PROFESIONES, 1959 Y 1967

(en bits y porcientos)

\begin{tabular}{llcc}
\hline & & 1959 & 1967 \\
\hline I & Concentración marginal & 1.1581 & 0.6620 \\
& interregional & $(72.85)$ & $(55.65)$ \\
II & Heterogeneidad interre- & 0.1568 & 0.1772 \\
& gional & $(9.98)$ & $(14.90)$ \\
III & Suma: concentración in- & 1.3149 & 0.8392 \\
& terregional media & $(82.71)$ & $(70.54)$ \\
IV & Concentración marginal & 0.1650 & 0.1350 \\
& intrarregional & $(10.38)$ & $(11.35)$ \\
V & Heterogeneidad & 0.1098 & 0.2154 \\
& & $(6.91)$ & $(18.11)$ \\
VI & Suma: concentración in- & 0.2748 & 0.3504 \\
& trarregional media & $(17.29)$ & $(29.46)$ \\
VII & Concentración marginal & 1.3231 & 0.7970 \\
& total (I + IV) & $(83.23)$ & $(67.00)$ \\
VIII & Heterogeneidad total & 0.2666 & 0.3926 \\
& (II + V) & $(16.77)$ & $(33.00)$ \\
IX & Suma: concentración & 1.5897 & 1.1896 \\
& total media (III + VI) & $(100.00)$ & $(100.00)$ \\
\hline
\end{tabular}

Nota: Los paréntesis indican porcientos.

11 Ibid. 
de la zona geográfica en sentido estadístico. La heterogeneidad mide, entonces, el grado de interdependencia entre las carreras y las zonas geográficas. Al nivel regional y dentro de cada región, la descomposición es la misma. Las cifras para 1959 y 1967 se resumen en el cuadro 3.

Como puede observarse, la heterogeneidad profesional a nivel nacional casi se duplica entre 1959 y 1967, lo cual significa una mayor interdependencia entre la zona geográfica y la carrera escogida. A este nivel la proporción que la heterogeneidad representa es de cierta importancia, pero lo es aun al nivel interno de las regiones. Ello significa que el estado dentro de la región determina significativamente la carrera estudiada y que en una proporción un poco menor es la región la que viene a determinarla. Nótese que el papel relativo de la interdependencia región-carrera y estado-carrera se invierte entre 1959 y 1967: en 1959 es más importante la heterogeneidad interregional que la intrarregional mientras que en 1967 sucede lo contrario.

En igual forma, la concentración por carrera puede descomponerse geográficamente. Se puede hablar de la concentración por carreras de los estudiantes del estado de Nuevo León o de la región norte. La relación que existe para estos términos es semejante a la analizada respecto a la concentración geográfica media de las carreras. La concentración profesional marginal (esto es, por carrera) del país más la heterogeneidad de la composición profesional al nivel interregional proporciona la concentración profesional regional media. A este resultado se agrega la heterogeneidad intrarregional para llegar al concepto de concentración profesional media de los estados. Estos cálculos se presentan en el cuadro 4.

Resumiendo, la concentración geográfica de la población escolar disminuyó en un $40 \%$ entre 1959 y 1967. El componente intrarregional

\section{CUADRo 4}

MÉXico: Concentractón REgronal DE estados y REgiones, 1959 y 1967

(En bits y en porcientos)

\begin{tabular}{lcc}
\hline & 1959 & 1967 \\
\hline Concentración profesional marginal & 0.8364 & 0.6564 \\
& $(75.83)$ & $(62.57)$ \\
Heterogeneidad interregional & 0.1568 & 0.1772 \\
& $(14.22)$ & $(16.89)$ \\
Suma: concentración profesional media & & 0.9932 \\
$\quad$ regional & $(90.05)$ & 0.8336 \\
& 0.1098 & $(79.46)$ \\
Heterogeneidad intrarregional & $(9.95)$ & 0.2154 \\
& & $(20.54)$ \\
Suma: concentración profesional media & 1.1030 & 1.0490 \\
de los estados & $(100.00)$ & $(100.00)$ \\
\hline
\end{tabular}

Nota: Las unidades en porcientos están entre paréntesis. 
disminuyó en términos absolutos pero explicó una mayor proporción de la concentración geográfica total al finalizar el período. Es al componente interregional al que puede atribuirse casi la totalidad del proceso de desconcentración. Todas las regiones se desconcentraron internamente menos la región occidente, lo cual se debió a la rápida expansión de las universidades de Jalisco. Los estados con centros universitarios de mayor desarrollo fueron los que contribuyeron con mayor proporción a la concentración intrarregional (Nuevo León y Jalisco).

En el período de estudio, la concentración por carrera disminuyó aunque a un ritmo mucho más lento que la geográfica. La concentración por carrera en 1967 resultó $21.5 \%$ menor que la de 1959, mientras que la geográfica había disminuido en un $40 \%$. A nivel nacional, la heterogeneidad de la composición profesional casi se duplicó en términos relativos, lo que implicó mayor interdependencia entre la zona geográfica y la carrera escogida por los estudiantes. Esta interdependencia fue mayor al nivel intrarregional. Es interesante señalar que al principio del período la interdependencia carrera-región tenía una importancia relativa mayor que la dependencia carrera-estado. Al final del mismo se invierte esta relación.

Conforme se fueron desarrollando las universidades de los estados y ampliando el número de carreras ofrecidas en ellas, los estudiantes podían permanecer en su estado de residencia para asistir a la universidad. Al principio del período, tenían que emigrar en mayores proporciones a otro estado dentro de la región, por lo que la variedad de carreras ofrecidas al nivel regional era la que determinaba cuál seguiría el alumno. De lo anterior se desprende que había mayor movilidad geográfica de los estudiantes universitarios en 1959 que en 1967. Algunos de ellos se trasladaban al Distrito Federal, pero no es posible determinar en qué proporción. En 1963, los estudiantes de procedencia escolar provincial representaron menos del $10 \%$ del primer ingreso a la Universidad Nacional.12

El proceso de desconcentración interregional no sólo es deseable, sino indispensable. En este sentido se ha logrado un gran avance en los últimos ocho años. En cambio, el que la población escolar se desconcentre dentro de cada región plantea serios problemas al sistema universitario. $\mathrm{La}$ existencia de una multitud de instituciones de educación superior (más de 85 según el directorio de la Asociación Nacional de Universidades) no es conveniente desde un punto de vista económico. La población escolar de 1967 no justifica la operación a una escala adecuada de más de 10 o 15 centros universitarios. Algunas instituciones cuentan con una población estudiantil muy elevada mientras que otras ofrecen carreras en que la población escolar es inferior a 50 alumnos. Las deseconomías de escala empiezan a cobrar importancia en algunas universidades. En otras no se dan aún economías de escala. Por ello, el desarrollo del concepto de universidad regional es importante.

12 Universidad Nacional Autónoma de México, Anuarios Estadísticos, 1961 a 1964. México, U.N.A.M. 


\section{APENNDICE *}

Se presentan a continuación algunas de las series de población escolar y número de egresados por carrera de las instituciones de educación superior en el país que el autor elaboró para los fines de su tesis antes mencionada. Hasta ahora, esta información no se había tabulado al nivel de carreras universitarias. La Asociación Nacional de Universidades e Institutos de Enseñanza Superior publicó en 1966 una serie de la población escolar de las instituciones asociadas para el período 1959-1966, por escuela profesional. 1 Dicha serie comprende únicamente las instituciones asociadas e incluye un número reducido de carreras subprofesionales. La Dirección General de Enseñanza Superior e Investigación Científica de la Secretaría de Educación Pública ha preparado, a partir de 1964, información estadística de la inscripción en instituciones de educación superior por grados escolares y escuela profesional. 2 La Oficina de Recursos Humanos del Banco de México realizó una estimación preliminar del número de egresados de instituciones de educación superior en el período 1959-1964, a un nivel bastante agregado. Dicha estimación se hizo con base en el número de egresados en $1964 .{ }^{3}$

No fue posible incluir en las series de población escolar y de egresados a la totalidad de las instituciones que ofrecen estudios superiores. Faltan algunas escuelas particulares de reciente creación o de existencia irregular cuya matrícula es muy reducida. Su omisión no afecta en forma significativa los totales de cada carrera.

Para efectos de este trabajo se han considerado como estudios profesionales aquellos que se realizan en instituciones de educación superior reconocidas por el Estado, cuya duración es de cuatro o más años y que requieren del alumno el haber terminado y aprobado previamente el bachillerato o su equivalente. Esta definición excluye algunas subprofesiones que se han incluido tradicionalmente en las estadísticas sobre educación superior, como es el caso de ingenieros topógrafos, trabajadoras sociales, parteras, metalurgistas, etc. La población escolar equivale al número de alumnos inscritos. Se considera como egresado al alumno inscrito en el último año de la carrera. En sentido estricto éstos no son egresados, razón

* El autor agradece al Lic. Alfonso Rangel Guerra y al Lic. Enrique Romero, Secretario Ejecutivo y Secretario Auxiliar, respectivamente, de la Asociación Nacional de Universidades e Institutos de Enseñanza Superior, el acceso a los archivos de la Asociación, fuente de la mayor parte de la información aquí presentada. El Prof. Pablo Xelhuantzi, Jefe del Departamento de Estadística Escolar de la Secretaría de Educación Pública, permitió consultar las fuentes directas de información. El Lic. Héctor Mayagoitia, Director General de Enseñanzas TecnoIógicas, Industriales y Comerciales, proporcionó información sobre los institutos tecnológicos regionales. Colaboradores de estas instituciones y dependencias prestaron una gran ayuda en la localización de los datos. Jorge Heredia colaboró en la etapa final de la elaboración de estas tabulaciones. A todos ellos el autor ofrece su más sincero reconocimiento. Desde luego que todos los errores cometidos en la elaboración y presentación finales de los datos son de la exclusiva responsabilidad del autor.

1 Asociación Nacional de Universidades e Institutos de Enseñanza Superior, La educación superior en México, 1966. Estado actual y problemas de financiamiento. México, 1966.

2 Secretaría de Educación Pública, Dirección General de Enseñanza Superior e Investigación Científica, Departamento de Estadística Escolar, Inscripción en universidades, institutos y escuetas de nivel superior por grados escolares en la República Mexicana, 1964, 1965 y 1966. Mimeografiado.

3 Publicada en V. L. Urquidi y A. Lajous Vargas, Educación superior, ciencia y tecnología en el desarrollo económico de México. Un estudio preliminar. México, El Colegio de México, 1967. 
por la cual las series resultan ligeramente sesgadas. Esta diferencia no es importante pues hay indicaciones de que la tasa de deserción es muy baja en el último año de una carrera. Esta cifra se ve afectada en forma más significativa por la calidad de la información que por el problema de definición.

No se han utilizado cifras del número de títulos expedidos, ${ }^{4}$ pues aunque existe diferencia formal entre el egresado y el titulado, en la práctica esta diferencia no afecta en esencia la posición profesional en muchos de los campos. Además, para el análisis de la corriente educativa es más importante la cifra de egresados, ya que son éstos los que dejan de ejercer presión sobre los recursos e instalaciones universitarios. Las modificaciones a los reglamentos de las universidades han producido recientemente cambios en las diferencias entre el número de egresados y de titulados que no reflejan cambios reales en la estructura de la población escolar.

Los cuadros que aparecen a continuación están basados en los informes presentados por los rectores y directores de instituciones de educación superior a la Asociación Nacional de Universidades e Institutos de Enseñanza Superior. Generalmente se utilizó el último informe enviado por los rectores en el transcurso de cada año académico. Esta información fue complementada con informes de los rectores a la Secretaría de Educación Pública. Se utilizaron directamente las boletas originales que se encuentran en el Departamento de Estadística Escolar de la Dirección General de Enseñanza Superior e Investigación Científica. En algunos casos fue necesario solicitar información a las mismas universidades.

Las cifras presentadas sólo intentan dar un orden de magnitud aproximado. El grado de confiabilidad de éstas varía de una institución a otra $\mathrm{e}$ inclusive entre las diferentes escuelas de una misma universidad. Son muchas las instituciones que no cuentan con un departamento de estadística escolar. Por lo general, la información está basada en el registro de boletas de inscripción, pero no son excepcionales las ocasiones en las que se basa en censos físicos. Los conceptos utilizados varían. La población escolar puede reflejar la matrícula al iniciarse los cursos o al finalizar los mismos. La información es distinta según la fuente de origen. No son raros los casos en los que diversos departamentos de una dependencia proporcionan cifras de población escolar significativamente diferentes. Todo aconseja ver con cierta reserva los cuadros elaborados.

En términos generales, la calidad de la información mejoró a partir de 1963. Fue entonces cuando la Asociación Nacional de Universidades empezó a pedir a los rectores datos de la población escolar por carrera, grado escolar y sexo. Fue necesario realizar algunas estimaciones que se hicieron utilizando técnicas estadísticas sencillas debido a que en muchos casos se trabajaba con números pequeños y series erráticas que hacían difícil encontrar tendencias claras. De 1963 a 1967 las estimaciones son pocas. A medida que se retrocedía en el tiempo éstas iban aumentando.

Los egresados de 1960 a 1962 de las instituciones de provincia fueron estimados para todas las carreras. Es importante señalar que éstas incluían menos de la tercera parte del total nacional. En ningún caso las estimaciones representaron el $50 \%$ de la cifra global, salvo en las series de humanidades y normal superior que son las más deficientes y erráticas debido a que no siempre fue posible excluir los cursos especiales y los por correspondencia. Los datos para 1967, al momento de hacer esta elaboración, quedan sujetos a revisión, pues las cifras de la Universidad Nacional son preliminares.

Las carreras se agruparon conforme a la siguiente clasificación:

4 Actualmente la Asociación Nacional de Universidades e Institutos de Enseñanza Superior está tabulando esta información. 
Ciencias administrativas: derecho, economía, ciencias políticas y sociales (incluye sociología, ciencia política, relaciones internacionales, diplomacia, administración pública, periodismo, etc.), contabilidad y administración dé empresas.

Ciencias naturales y exactas: física y matemáticas (incluye actuaría, física teórica, física experimental, matemáticas, etc.) y biología.

Ciencias quimicas: química (incluye química, química industrial, química agrícola, etc.), ingeniería química, química farmaco-biológica (incluye químico farmacéutico industrial) y otras químicas (incluye ingeniería bioquímica y químico bacteriólogo y parasitólogo).

Ingenierias: arquitectura (incluye ingeniero-arquitecto), civil, mecánicoelectricista (incluye ingeniería mecánica, ingeniería eléctrica, etc.), minerometalúrgica (incluye ingeniería de minas e ingeniero metalúrgico), industrial, otras ingenierías (incluye geología, ingeniería petrolera, textil, aeronáutica, electrónica, comunicaciones, municipal, etc.).

Grupo agropecuario: agronomía (incluye ingeniero agrónomo en todas sus especialidades) y veterinaria.

Ciencias médicas: medicina y odontología.

Humanidades: filosofía, letras, historia, antropologia, psicología, pedagogía, normal superior en todas las especialidades, etc.

Otras: ciencias y técnicas de la información, oceanología, diseño industrial, relaciones industriales, etc. 
Cuadro A-1

México: Población escolar total en INSTITUciones DE EDUCACIÓN SUPERIOR, POR RAMa PROFesional Y POR CARRERA, 1959-1967

\begin{tabular}{|c|c|c|c|c|c|c|c|c|c|c|c|}
\hline & \multirow[b]{2}{*}{1959} & \multirow[b]{2}{*}{1960} & \multirow[b]{2}{*}{2961} & \multirow[b]{2}{*}{1962} & \multirow[b]{2}{*}{1963} & \multirow[b]{2}{*}{1964} & \multirow[b]{2}{*}{2965} & \multirow[b]{2}{*}{1966} & \multirow[b]{2}{*}{1967} & \multicolumn{2}{|c|}{$\begin{array}{l}\text { Distribucion } \\
\text { porcentual }\end{array}$} \\
\hline & & & & & & & & & & 1959 & 1967 \\
\hline Total necional & 69330 & 77033 & 86524 & 95897 & 103178 & 111341 & 126380 & 136411 & 144937 & 100.00 & 100.00 \\
\hline $\begin{array}{l}\text { Clencias administrativas } \\
\text { Derecho } \\
\text { Bconomfo } \\
\text { Ciencias polfticas y socialos } \\
\text { Contabilidad } \\
\text { Administración de empresas }\end{array}$ & $\begin{array}{rl}20 & 782 \\
9 & 496 \\
1 & 900 \\
516 \\
7918 \\
952\end{array}$ & $\begin{array}{rl}24 & 392 \\
10 & 745 \\
2 & 390 \\
629 \\
9125 \\
1503\end{array}$ & $\begin{array}{r}27928 \\
11742 \\
2762 \\
1052 \\
10726 \\
2046\end{array}$ & $\begin{array}{rl}32 & 311 \\
13222 \\
3320 \\
7722 \\
12532 \\
2515\end{array}$ & $\begin{array}{r}36509 \\
14.070 \\
3783 \\
787 \\
14710 \\
3159\end{array}$ & $\begin{array}{rl}41 & 012 \\
15418 \\
4171 \\
946 \\
16625 \\
3852\end{array}$ & $\begin{array}{rl}47 & 430 \\
17020 \\
4815 \\
1128 \\
19378 \\
5089\end{array}$ & $\begin{array}{rl}51 & 769 \\
17 & 682 \\
5379 \\
11264 \\
21553 \\
5891\end{array}$ & $\begin{array}{rl}53 & 436 \\
17 & 826 \\
5 & 775 \\
1 & 468 \\
21 & 831 \\
6 & 536\end{array}$ & $\begin{array}{r}29.97 \\
13.70 \\
2.74 \\
0.74 \\
11.42 \\
1.37\end{array}$ & $\begin{array}{r}36.86 \\
12.30 \\
3.98 \\
1.01 \\
15.06 \\
4.51\end{array}$ \\
\hline 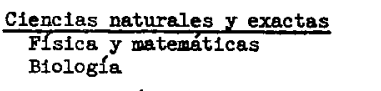 & $\begin{array}{l}989 \\
560 \\
429\end{array}$ & $\begin{array}{r}1257 \\
715 \\
542\end{array}$ & $\begin{array}{r}1509 \\
901 \\
608\end{array}$ & $\begin{array}{l}1754 \\
1070 \\
684\end{array}$ & $\begin{array}{rl}2 & 119 \\
1 & 369 \\
750\end{array}$ & $\begin{array}{l}2601 \\
1767 \\
834\end{array}$ & $\begin{array}{r}3080 \\
2096 \\
984\end{array}$ & $\begin{array}{l}3402 \\
2340 \\
1062\end{array}$ & $\begin{array}{l}3880 \\
2601 \\
1279\end{array}$ & $\begin{array}{l}1.43 \\
0.81 \\
0.62\end{array}$ & $\begin{array}{l}2.68 \\
1.80 \\
0.88\end{array}$ \\
\hline 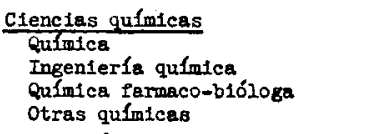 & $\begin{array}{l}5834 \\
807 \\
3562 \\
1167 \\
298\end{array}$ & $\begin{array}{l}5978 \\
813 \\
3627 \\
1200 \\
338\end{array}$ & $\begin{array}{r}6530 \\
891 \\
4005 \\
1267 \\
367\end{array}$ & $\begin{array}{l}6875 \\
928 \\
4214 \\
2342 \\
391\end{array}$ & $\begin{array}{r}6867 \\
876 \\
4245 \\
1363 \\
383\end{array}$ & $\begin{array}{r}7580 \\
837 \\
4739 \\
1 \quad 463 \\
541\end{array}$ & $\begin{array}{r}8221 \\
965 \\
5091 \\
1605 \\
560\end{array}$ & $\begin{array}{r}8888 \\
955 \\
5557 \\
1749 \\
627\end{array}$ & $\begin{array}{rl}10 & 416 \\
1 & 003 \\
6 & 539 \\
1 & 993 \\
& 881\end{array}$ & $\begin{array}{l}8.41 \\
3.16 \\
5.14 \\
1.68 \\
0.43\end{array}$ & $\begin{array}{l}7.19 \\
0.69 \\
4.51 \\
1.38 \\
0.61\end{array}$ \\
\hline $\begin{array}{l}\text { Ingenieria } \\
\text { Aqquitectura } \\
\text { c1vil } \\
\text { Meánico-eléctrices } \\
\text { M1nero-metalúrgca } \\
\text { Industrial } \\
\text { otras 1ngenierfas }\end{array}$ & $\begin{array}{rl}19 & 406 \\
5071 \\
6802 \\
5021 \\
289 \\
223 \\
2000\end{array}$ & $\begin{array}{r}20806 \\
5456 \\
7100 \\
5699 \\
208 \\
256 \\
2087\end{array}$ & $\begin{array}{rl}23 & 191 \\
6 & 174 \\
7410 \\
6701 \\
208 \\
293 \\
2225\end{array}$ & $\begin{aligned} 25099 \\
6631 \\
7615 \\
7681 \\
249 \\
682 \\
2241\end{aligned}$ & $\begin{array}{rl}26 & 797 \\
7 & 020 \\
7734 \\
8392 \\
236 \\
1024 \\
2391\end{array}$ & $\begin{array}{rl}27 & 545 \\
7 & 117 \\
7 & 744 \\
8 & 673 \\
250 \\
1427 \\
2 \\
2334\end{array}$ & $\begin{array}{rl}29 & 162 \\
7 & 014 \\
8382 \\
9342 \\
270 \\
2737 \\
17418\end{array}$ & $\begin{array}{r}31395 \\
7128 \\
8344 \\
10474 \\
337 \\
2178 \\
2934\end{array}$ & $\begin{array}{rl}33 & 729 \\
7125 \\
9142 \\
11577 \\
411 \\
2467 \\
3007\end{array}$ & $\begin{array}{l}27.99 \\
7.31 \\
9.81 \\
7.24 \\
0.42 \\
0.32 \\
2.89\end{array}$ & $\begin{array}{l}23.27 \\
4.92 \\
6.31 \\
7.99 \\
0.28 \\
1.70 \\
2.07\end{array}$ \\
\hline 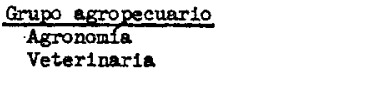 & $\begin{array}{r}1537 \\
746 \\
791\end{array}$ & $\begin{array}{l}1948 \\
845 \\
1103\end{array}$ & $\begin{array}{l}2325 \\
972 \\
1353\end{array}$ & $\begin{array}{l}2533 \\
2049 \\
2584\end{array}$ & $\begin{array}{l}3049 \\
1237 \\
1812\end{array}$ & $\begin{array}{l}3206 \\
1274 \\
1 \quad 932\end{array}$ & $\begin{array}{l}4023 \\
1652 \\
2371\end{array}$ & 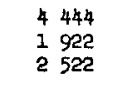 & 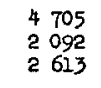 & $\begin{array}{l}2.22 \\
1.08 \\
1.14\end{array}$ & $\begin{array}{l}3.25 \\
1.45 \\
1.80\end{array}$ \\
\hline$\frac{\text { C1encias médices }}{\text { Medicins }}$ & $\begin{array}{r}14154 \\
12747 \\
1407\end{array}$ & $\begin{array}{rl}15 & 149 \\
13 & 442 \\
1 & 707\end{array}$ & $\begin{aligned} 16251 \\
14298 \\
1953\end{aligned}$ & $\begin{array}{l}17453 \\
15242 \\
2211\end{array}$ & $\begin{array}{r}18653 \\
36212 \\
2441\end{array}$ & $\begin{array}{r}19518 \\
16914 \\
2604\end{array}$ & $\begin{array}{rl}20 & 740 \\
17878 \\
2862\end{array}$ & $\begin{array}{rl}21 & 648 \\
18 & 3 \pi 7 \\
3 & 271\end{array}$ & $\begin{array}{r}23269 \\
19512 \\
3757\end{array}$ & $\begin{array}{r}20.42 \\
18.39 \\
2.03\end{array}$ & $\begin{array}{l}16.05 \\
13.46 \\
2.59\end{array}$ \\
\hline Husanidades & 6528 & 7373 & 8590 & 9494 & 8785 & 9315 & 13055 & 14210 & 14870 & 9.42 & 10.26 \\
\hline otres & 100 & 130 & 200 & 278 & 399 & 564 & 669 & 655 & 632 & 0.14 & 0.44 \\
\hline
\end{tabular}

Fuente: Véase la nota introductoria de este apéndice en cuanto a las fuentes el concepto de "educación superior", las limitaciones de los datos y el contenido de cada uno de los rubros de las ramas profesionales y las carreras. 
Cuadro A-2

México: Población escolar en instituciones de educación superior, Distrito Federal y resto del pafs, $1959-1967$

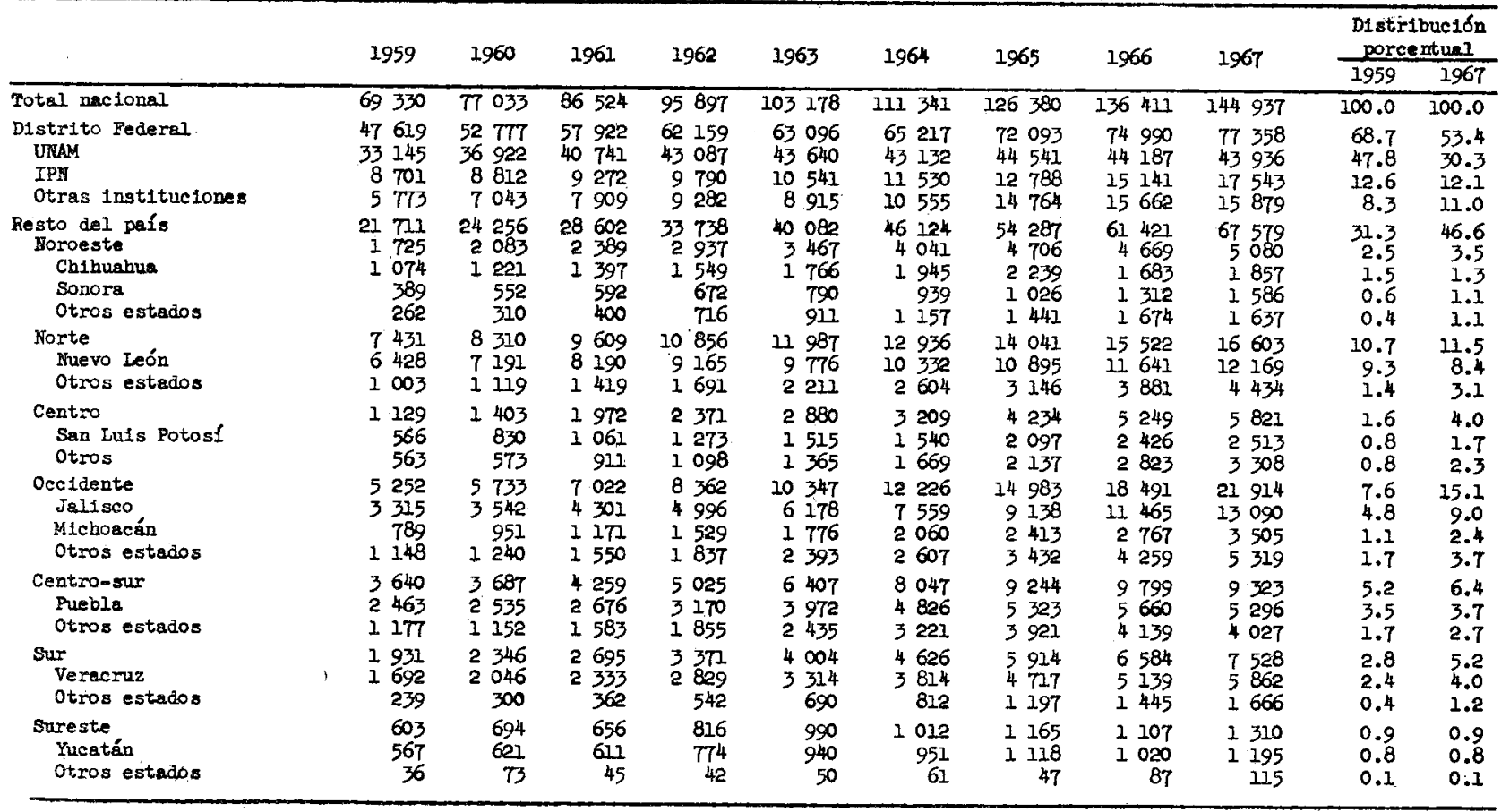

Fuente: Asociación Nacional de Universidades e Institutos de Enseñanza Superior. Véase la nota introductoria de este apéndice con relación a la definición empleada de población escolar universitaria y a las limitaciones que presenta esta información. EI presente cuadro resume información detallada, por institución, recopilada por la

Nota: UNAM, Universidad Nacional Autónoma de México; IPN, Instituto Politécnico Nacional. 
Cuadro A-3

MÉXico: Población de 20 a 24 AÑos, POR REgIóN y POR ESTADO, 1959-1967

(En miles)

\begin{tabular}{|c|c|c|c|c|c|c|c|c|c|}
\hline Región y estado & 1959 & 1960 & 2961 & 1962 & 1963 & 1964 & 1965 & 1966 & 2967 \\
\hline $\begin{array}{l}\text { Total nacional } \\
\text { D. F. } \\
\text { Resto del país }\end{array}$ & $\begin{array}{r}2884.1 \\
436.2 \\
2448.1\end{array}$ & $\begin{array}{r}2977.4 \\
449.7 \\
2527.7\end{array}$ & $\begin{array}{r}3073.0 \\
463.6 \\
2609.4\end{array}$ & $\begin{array}{l}3172.7 \\
478.0 \\
2694.7\end{array}$ & $\begin{array}{r}3274.8 \\
492.8 \\
2782.0\end{array}$ & $\begin{array}{r}3380.9 \\
508.1 \\
2872.3\end{array}$ & $\begin{array}{r}3492.9 \\
523.9 \\
2969.0\end{array}$ & $\begin{array}{l}3630.1 \\
=550.3 \\
3079.8\end{array}$ & $\begin{array}{r}3773.8 \\
578.1 \\
3195.7\end{array}$ \\
\hline $\begin{array}{l}\text { Noroeste } \\
\text { B. C. Norte } \\
\text { B. C. Sur } \\
\text { Chibuahua } \\
\text { Sinaloa } \\
\text { Sonora }\end{array}$ & $\begin{array}{r}285.4 \\
35.0 \\
6.5 \\
108.0 \\
69.3 \\
66.6\end{array}$ & $\begin{array}{r}298.0 \\
38.7 \\
6.7 \\
111.4 \\
72.0 \\
69.2\end{array}$ & $\begin{array}{r}311.3 \\
42.8 \\
6.9 \\
114.9 \\
74.8 \\
71.9\end{array}$ & $\begin{array}{r}325.3 \\
4.3 \\
7.1 \\
11.8 .6 \\
77.7 \\
74.6\end{array}$ & $\begin{array}{r}340.2 \\
52.2 \\
7.4 \\
322.3 \\
80.7 \\
77.6\end{array}$ & $\begin{array}{r}355.8 \\
57.7 \\
7.6 \\
126.2 \\
83.8 \\
80.5\end{array}$ & $\begin{array}{r}372.6 \\
63.8 \\
7.9 \\
130.2 \\
87.1 \\
83.6\end{array}$ & $\begin{array}{r}393.9 \\
71.2 \\
8.1 \\
136.8 \\
89.8 \\
88.0\end{array}$ & $\begin{array}{r}416.7 \\
79.5 \\
8.3 \\
143.7 \\
92.6 \\
92.6\end{array}$ \\
\hline $\begin{array}{l}\text { Norte } \\
\text { Coahulia } \\
\text { Muevo León } \\
\text { Tamaulipas }\end{array}$ & $\begin{array}{r}263.0 \\
76.3 \\
99.0 \\
87.7\end{array}$ & $\begin{array}{r}271.1 \\
78.2 \\
102.3 \\
90.6\end{array}$ & $\begin{array}{r}279.4 \\
80.1 \\
105.7 \\
93.6\end{array}$ & $\begin{array}{r}288.2 \\
82.1 \\
109.3 \\
96.8\end{array}$ & $\begin{array}{r}297.1 \\
84.1 \\
113.0 \\
100.0\end{array}$ & $\begin{array}{r}306.3 \\
86.1 \\
116.8 \\
103.4\end{array}$ & $\begin{array}{r}315.9 \\
88.3 \\
120.7 \\
106.9\end{array}$ & $\begin{array}{r}327.3 \\
89.9 \\
125.8 \\
111.6\end{array}$ & $\begin{array}{r}339.3 \\
91.5 \\
131.2 \\
116.6\end{array}$ \\
\hline $\begin{array}{l}\text { Centro } \\
\text { Aguascalientes } \\
\text { Durango } \\
\text { Querétaro } \\
\text { San Luis P. } \\
\text { Zacatecas }\end{array}$ & $\begin{array}{r}265.4 \\
18.7 \\
65.9 \\
27.6 \\
88.2 \\
65.0\end{array}$ & $\begin{array}{r}270.9 \\
19.2 \\
66.8 \\
28.4 \\
89.7 \\
66.8\end{array}$ & $\begin{array}{l}276.4 \\
19.7 \\
67.7 \\
29.2 \\
91.2 \\
68.6\end{array}$ & $\begin{array}{r}282.3 \\
20.3 \\
68.6 \\
30.1 \\
92.8 \\
70.5\end{array}$ & $\begin{array}{r}288.0 \\
20.8 \\
69.4 \\
31.0 \\
94.4 \\
72.4\end{array}$ & $\begin{array}{r}294.0 \\
21.4 \\
70.3 \\
31.9 \\
96.0 \\
74.4\end{array}$ & $\begin{array}{l}300.1 \\
21.9 \\
71.3 \\
32.8 \\
97.7 \\
76.4\end{array}$ & $\begin{array}{r}304.7 \\
22.2 \\
72.1 \\
33.1 \\
100.1 \\
77.2\end{array}$ & $\begin{array}{r}309.4 \\
22.5 \\
72.9 \\
33.4 \\
102.6 \\
78.0\end{array}$ \\
\hline $\begin{array}{l}\text { Occldente } \\
\text { Colima } \\
\text { Guanajuato } \\
\text { Jalisco } \\
\text { Michoacán } \\
\text { Nayarit }\end{array}$ & $\begin{array}{r}513.0 \\
12.8 \\
134.6 \\
189.9 \\
145.7 \\
30.0\end{array}$ & $\begin{array}{r}531.9 \\
13.3 \\
139.4 \\
198.2 \\
149.6 \\
31.4\end{array}$ & $\begin{array}{r}551.6 \\
13.8 \\
144.4 \\
206.9 \\
153.7 \\
32.8\end{array}$ & $\begin{array}{r}572.1 \\
14.4 \\
149.6 \\
216.0 \\
157.8 \\
34.3\end{array}$ & $\begin{array}{r}593.3 \\
14.9 \\
154.9 \\
225.5 \\
162.1 \\
35.9\end{array}$ & $\begin{array}{r}615.3 \\
15.5 \\
160.5 \\
235.3 \\
166.5 \\
37.5\end{array}$ & $\begin{array}{r}638.2 \\
16.1 \\
166.2 \\
245.7 \\
171.0 \\
39.2\end{array}$ & $\begin{array}{r}659.3 \\
16.7 \\
171.1 \\
254.7 \\
176.2 \\
40.6\end{array}$ & $\begin{array}{r}681.2 \\
17.3 \\
176.2 \\
264.0 \\
181.6 \\
42.1\end{array}$ \\
\hline $\begin{array}{l}\text { Centro sur } \\
\text { Guerrero } \\
\text { Hidalgo } \\
\text { México } \\
\text { Morelos } \\
\text { Puebla } \\
\text { Tlaxcala }\end{array}$ & $\begin{array}{r}526.6 \\
98.6 \\
78.7 \\
150.3 \\
30.8 \\
142.4 \\
25.8\end{array}$ & $\begin{array}{r}545.6 \\
101.2 \\
80.7 \\
155.9 \\
32.0 \\
249.2 \\
26.6\end{array}$ & $\begin{array}{r}565.4 \\
103.9 \\
82.8 \\
161.7 \\
33.3 \\
156.3 \\
27.4\end{array}$ & $\begin{array}{r}586.0 \\
106.7 \\
85.0 \\
167.8 \\
34.6 \\
163.7 \\
28.2\end{array}$ & $\begin{array}{r}607.3 \\
109.6 \\
87.2 \\
174.0 \\
36.0 \\
172.5 \\
29.0\end{array}$ & $\begin{array}{r}629.3 \\
112.5 \\
89.4 \\
180.6 \\
37.4 \\
179.6 \\
29.8\end{array}$ & $\begin{array}{r}652.4 \\
115.5 . \\
91.7 \\
187.3 \\
38.9 \\
188.3 \\
30.7\end{array}$ & $\begin{array}{r}679.6 \\
119.6 \\
94.1 \\
199.4 \\
41.2 \\
193.8 \\
31.5\end{array}$ & $\begin{array}{r}708.2 \\
123.9 \\
96.5 \\
212.3 \\
43.6 \\
299.5 \\
32.4\end{array}$ \\
\hline $\begin{array}{l}\frac{\text { sur }}{\text { ChIapas }} \\
\text { Daxaca } \\
\text { Tabaseo } \\
\text { Veracruz }\end{array}$ & $\begin{array}{r}528.6 \\
106.3 \\
144.3 \\
42.6 \\
235.4\end{array}$ & $\begin{array}{r}541.4 \\
108.6 \\
146.5 \\
43.9 \\
242.4\end{array}$ & $\begin{array}{r}554.4 \\
110.9 \\
148.7 \\
45.2 \\
249.6\end{array}$ & $\begin{array}{r}567.8 \\
113.3 \\
151.0 \\
46.5 \\
257.0\end{array}$ & $\begin{array}{l}580.8 \\
115.7 \\
153.3 \\
47.8 \\
264.0\end{array}$ & $\begin{array}{r}595.5 \\
118.2 \\
155.7 \\
49.2 \\
272.4\end{array}$ & $\begin{array}{r}610.0 \\
120.7 \\
158.2 \\
50.6 \\
280.5\end{array}$ & $\begin{array}{r}632.5 \\
125.4 \\
162.4 \\
52.2 \\
292.5\end{array}$ & $\begin{array}{r}655.7 \\
130.2 \\
166.7 \\
53.8 \\
305.0\end{array}$ \\
\hline $\begin{array}{l}\text { Sureste } \\
\text { Campeche } \\
\text { Quintana Roo } \\
\text { Yucatán }\end{array}$ & $\begin{array}{r}66.8 \\
13.7 \\
4.6 \\
48.5\end{array}$ & $\begin{array}{r}68.8 \\
14.0 \\
4.7 \\
50.1\end{array}$ & $\begin{array}{r}70.9 \\
14.4 \\
4.8 \\
51.7\end{array}$ & $\begin{array}{r}73.0 \\
24.7 \\
4.9 \\
53.4\end{array}$ & $\begin{array}{r}75.3 \\
15.1 \\
5.1 \\
55.1\end{array}$ & $\begin{array}{r}77.6 \\
15.5 \\
5.2 \\
56.9\end{array}$ & $\begin{array}{r}79.8 \\
15.8 \\
5.3 \\
58.7\end{array}$ & $\begin{array}{r}82.5 \\
16.3 \\
5.8 \\
60.4\end{array}$ & $\begin{array}{r}85.2 \\
16.8 \\
6.2 \\
62.2\end{array}$ \\
\hline
\end{tabular}

Fuente: Cálculos basados en Raúl Benítez Zenteno y Gustavo Cabrera, Proyecciones de ta población de México, 1960-1980. México, Banco de México, 1966. 


\section{Cuadro A-4}

México: Participación de la población universitaria en el gRUPo de EDad DE 20 A 24 AÑOS, POR REGIÓN Y ESTADO, 1959-1967

(En porcientos)

\begin{tabular}{|c|c|c|c|c|c|c|c|c|c|}
\hline Reglón y estado & 1959 & 1960 & 1961 & 1962 & 1963 & 1964 & 1965 & 1966 & 1967 \\
\hline $\begin{array}{l}\text { Total nacional } \\
\text { D.F. } \\
\text { Resto del país }\end{array}$ & $\begin{array}{r}2.40 \\
10.91 \\
0.88\end{array}$ & $\begin{array}{r}2.58 \\
11.73 \\
0.95\end{array}$ & $\begin{array}{r}2.81 \\
12.49 \\
1.09\end{array}$ & $\begin{array}{r}3.02 \\
13.00 \\
1.25\end{array}$ & $\begin{array}{r}3.15 \\
12.96 \\
1.44\end{array}$ & $\begin{array}{r}3.29 \\
12.83 \\
1.60\end{array}$ & $\begin{array}{r}3.61 \\
13.76 \\
1.82\end{array}$ & $\begin{array}{r}3.75 \\
13.62 \\
1.99\end{array}$ & $\begin{array}{r}3.84 \\
13.38 \\
2.11\end{array}$ \\
\hline $\begin{array}{l}\text { Noroeste } \\
\text { B.C. Norte } \\
\text { B.C. Sur } \\
\text { Chibuahua } \\
\text { Sinaloa } \\
\text { Sonora }\end{array}$ & $\begin{array}{l}0.60 \\
- \\
- \\
0.99 \\
0.37 \\
0.58\end{array}$ & $\begin{array}{l}0.69 \\
- \\
- \\
1.09 \\
0.43 \\
0.79\end{array}$ & $\begin{array}{l}0.76 \\
0.16 \\
- \\
1.21 \\
0.43 \\
0.82\end{array}$ & $\begin{array}{l}0.90 \\
0.41 \\
- \\
1.30 \\
0.66 \\
0.90\end{array}$ & $\begin{array}{l}1.01 \\
0.46 \\
- \\
1.44 \\
0.82 \\
1.01\end{array}$ & $\begin{array}{l}1.13 \\
0.61 \\
- \\
1.54 \\
0.95 \\
1.16\end{array}$ & $\begin{array}{l}1.26 \\
0.64 \\
- \\
1.71 \\
1.18 \\
1.22\end{array}$ & $\begin{array}{l}1.18 \\
0.79 \\
- \\
1.23 \\
1.23 \\
1.49\end{array}$ & $\begin{array}{l}1.21 \\
0.87 \\
- \\
1.29 \\
1.01 \\
1.71\end{array}$ \\
\hline $\begin{array}{l}\text { Norte } \\
\text { Coahuila } \\
\text { Nhevo León } \\
\text { Tamaulipas }\end{array}$ & $\begin{array}{l}2.82 \\
0.74 \\
6.49 \\
0.49\end{array}$ & $\begin{array}{l}3.06 \\
0.81 \\
7.02 \\
0.53\end{array}$ & $\begin{array}{l}3.43 \\
1.08 \\
7.74 \\
0.58\end{array}$ & $\begin{array}{l}3.76 \\
1.21 \\
8.38 \\
0.72\end{array}$ & $\begin{array}{l}4.03 \\
1.50 \\
8.65 \\
0.94\end{array}$ & $\begin{array}{l}4.23 \\
1.70 \\
8.84 \\
1.12\end{array}$ & $\begin{array}{l}4.44 \\
1.95 \\
9.02 \\
1.33\end{array}$ & $\begin{array}{l}4.74 \\
2.26 \\
9.25 \\
1.65\end{array}$ & $\begin{array}{l}4.89 \\
2.55 \\
9.27 \\
1.80\end{array}$ \\
\hline $\begin{array}{l}\text { Centro } \\
\text { Aguascalientes } \\
\text { Durango } \\
\text { Querétaro } \\
\text { San Lu1s P. } \\
\text { Zacatecas }\end{array}$ & $\begin{array}{l}0.42 \\
-. \\
0.21 \\
1.26 \\
0.64 \\
0.11\end{array}$ & $\begin{array}{l}0.51 \\
- \\
0.25 \\
1.02 \\
0.92 \\
0.16\end{array}$ & $\begin{array}{l}0.71 \\
-. \\
0.37 \\
1.41 \\
1.16 \\
0.36\end{array}$ & $\begin{array}{l}0.83 \\
- \\
0.47 \\
1.33 \\
1.37 \\
0.52\end{array}$ & $\begin{array}{l}1.00 \\
- \\
0.65 \\
1.43 \\
1.60 \\
0.63\end{array}$ & $\begin{array}{l}1.09 \\
- \\
0.81 \\
1.48 \\
1.60 \\
0.83\end{array}$ & $\begin{array}{l}1.41 \\
- \\
0.94 \\
1.76 \\
2.14 \\
1.15\end{array}$ & $\begin{array}{l}1.72 \\
- \\
1.12 \\
1.98 \\
2.42 \\
1.75\end{array}$ & $\begin{array}{l}1.88 \\
-. \\
1.29 \\
2.05 \\
2.44 \\
2.15\end{array}$ \\
\hline $\begin{array}{l}\frac{\text { Occidente }}{\text { Col1ma }} \\
\text { Guanajuato } \\
\text { Jalisco } \\
\text { M1choacán } \\
\text { Nayarit }\end{array}$ & $\begin{array}{l}1.02 \\
0.69 \\
0.69 \\
1.74 \\
0.54 \\
0.70\end{array}$ & $\begin{array}{l}1.07 \\
0.18 \\
0.71 \\
1.78 \\
0.63 \\
0.70\end{array}$ & $\begin{array}{l}1.27 \\
0.26 \\
0.76 \\
2.07 \\
0.76 \\
1.25\end{array}$ & $\begin{array}{l}1.46 \\
0.25 \\
0.89 \\
2.31 \\
0.96 \\
1.34 .\end{array}$ & $\begin{array}{l}1.74 \\
0.89 \\
1.06 \\
2.73 \\
1.09 \\
1.71\end{array}$ & $\begin{array}{l}1.98 \\
0.85 \\
1.09 \\
3.21 \\
1.23 \\
1.91\end{array}$ & $\begin{array}{l}2.34 \\
1.24 \\
1.10 \\
3.71 \\
1.41 \\
3.54\end{array}$ & $\begin{array}{l}2.80 \\
1.16 \\
1.18 \\
4.50 \\
1.57 \\
5.01\end{array}$ & $\begin{array}{l}3.21 \\
1.46 \\
1.29 \\
4.95 \\
1.93 \\
6.60\end{array}$ \\
\hline $\begin{array}{l}\text { Centro sur } \\
\text { Guerrero } \\
\text { Hidalgo } \\
\text { México } \\
\text { Morelos } \\
\text { Puebla } \\
\text { Tlaxcala }\end{array}$ & $\begin{array}{l}0.69 \\
0.09 \\
0.27 \\
0.49 \\
0.40 \\
1.72 \\
-\end{array}$ & $\begin{array}{l}0.67 \\
0.11 \\
0.29 \\
0.45 \\
0.29 \\
1.69 \\
-\end{array}$ & $\begin{array}{l}0.75 \\
0.09 \\
0.45 \\
0.58 \\
0.45 \\
1.71 \\
-\end{array}$ & $\begin{array}{l}0.85 \\
0.10 \\
0.44 \\
0.69 \\
0.59 \\
1.93 \\
-\end{array}$ & $\begin{array}{l}1.05 \\
0.13 \\
0.63 \\
0.84 \\
0.78 \\
1.90 \\
-\end{array}$ & $\begin{array}{l}1.27 \\
0.18 \\
0.83 \\
0.98 \\
1.32 \\
2.68 \\
-\end{array}$ & $\begin{array}{l}1.41 \\
0.25 \\
0.83 \\
1.16 \\
1.67 \\
2.82 \\
0.08\end{array}$ & $\begin{array}{l}1.44 \\
0.26 \\
0.71 \\
1.08 \\
2.26 \\
2.92 \\
0.16\end{array}$ & $\begin{array}{l}1.31 \\
0.34 \\
0.79 \\
0.79 \\
2.47 \\
2.65 \\
0.20\end{array}$ \\
\hline $\begin{array}{l}\text { Sur } \\
\text { Chiapas } \\
\text { Oaxaca } \\
\text { Tabasco } \\
\text { Veracruz }\end{array}$ & $\begin{array}{l}0.36 \\
0.04 \\
0.07 \\
0.18 \\
0.71\end{array}$ & $\begin{array}{l}0.43 \\
0.04 \\
0.08 \\
0.28 \\
0.84\end{array}$ & $\begin{array}{l}0.48 \\
0.05 \\
0.11 \\
0.30 \\
0.93\end{array}$ & $\begin{array}{l}0.59 \\
0.06 \\
0.15 \\
0.48 \\
1.10\end{array}$ & $\begin{array}{l}0.68 \\
0.08 \\
0.20 \\
0.60 \\
1.25\end{array}$ & $\begin{array}{l}0.77 \\
0.10 \\
0.22 \\
0.68 \\
1.40\end{array}$ & $\begin{array}{l}0.96 \\
0.10 \\
0.28 \\
1.22 \\
1.68\end{array}$ & $\begin{array}{l}1.04 \\
0.11 \\
0.34 \\
1.40 \\
1.75\end{array}$ & $\begin{array}{l}1.14 \\
0.12 \\
0.37 \\
1.63 \\
1.92\end{array}$ \\
\hline $\begin{array}{l}\frac{\text { Sureste }}{\text { Campeche }} \\
\text { Quintana Roo } \\
\text { Yucatán }\end{array}$ & $\begin{array}{l}0.90 \\
0.26 \\
- \\
1.16\end{array}$ & $\begin{array}{l}1.00 \\
0.52 \\
- \\
1.23\end{array}$ & $\begin{array}{l}0.92 \\
0.31 \\
= \\
1.18\end{array}$ & $\begin{array}{l}1.11 \\
0.28 \\
- \\
1.44\end{array}$ & $\begin{array}{l}1.31 \\
0.33 \\
- \\
1.70\end{array}$ & $\begin{array}{c}1.30 \\
0.39 \\
- \\
1.67\end{array}$ & $\begin{array}{l}1.45 \\
0.29 \\
- \\
1.90\end{array}$ & $\begin{array}{l}1.34 \\
0.53 \\
= \\
1.68\end{array}$ & $\begin{array}{c}1.53 \\
0.68 \\
- \\
1.92\end{array}$ \\
\hline
\end{tabular}

Fuente: Con base en las citadas en los cuadros A-2 y A-3. 
Cuadro A-5

MÉxico: EgResados de INSTITUCIONES DE EDUCACIÓN SUPERIOR, POR RAMA PROFESTONAL Y POR CARRERA, 1960-1967 *

\begin{tabular}{|c|c|c|c|c|c|c|c|c|c|c|}
\hline & \multirow[b]{2}{*}{1960} & \multirow[b]{2}{*}{.1962} & \multirow[b]{2}{*}{1962} & \multirow[b]{2}{*}{1963} & \multirow[b]{2}{*}{1964} & \multirow[b]{2}{*}{1965} & \multirow[b]{2}{*}{1966} & \multirow[b]{2}{*}{1967} & \multicolumn{2}{|c|}{$\begin{array}{c}\text { Distribuc 1ón } \\
\text { porcentuel }\end{array}$} \\
\hline & & & & & & & & & & 1967 \\
\hline Total nacional & 8400 & 9320 & 10795 & 11743 & 13109 & 15241 & 17987 & 18553 & 100.00 & 100.00 \\
\hline $\begin{array}{l}\text { C1encias administratives } \\
\begin{array}{l}\text { Derecho } \\
\text { Economis }\end{array}\end{array}$ & $\begin{array}{rl}2 & 454 \\
1396 \\
185\end{array}$ & $\begin{array}{l}2760 \\
1559 \\
183\end{array}$ & $\begin{array}{l}3250 \\
1770 \\
235\end{array}$ & $\begin{array}{rl}3 & 499 \\
1 & 624 \\
272\end{array}$ & $\begin{array}{l}4121 \\
1728 \\
390\end{array}$ & $\begin{array}{l}5109 \\
1932 \\
452\end{array}$ & $\begin{array}{l}6169 \\
2358 \\
543\end{array}$ & $\begin{array}{l}6236 \\
2086 \\
591\end{array}$ & $\begin{array}{r}29.21 \\
16.62 \\
2.20\end{array}$ & $\begin{array}{r}33.61 \\
11.24 \\
3.19\end{array}$ \\
\hline $\begin{array}{l}\text { Clencias politicas y socia- } \\
\text { les } \\
\text { Contabilidida } \\
\text { Administración de empresas }\end{array}$ & $\begin{array}{r}80 \\
696 \\
97\end{array}$ & $\begin{array}{l}999 \\
817 \\
102\end{array}$ & $\begin{array}{r}67 \\
1043 \\
135\end{array}$ & $1 \begin{array}{r}51 \\
380 \\
170\end{array}$ & $\begin{array}{rl} & 62 \\
2 & 77 . \\
170\end{array}$ & $\begin{array}{r}88 \\
2303 \\
334\end{array}$ & $=\begin{array}{r}120 \\
2644 \\
504\end{array}$ & $\begin{array}{r}136 \\
2881 \\
542\end{array}$ & $\begin{array}{l}0.95 \\
8.29 \\
1.15\end{array}$ & $\begin{array}{r}0.73 \\
15.53 \\
2.92\end{array}$ \\
\hline$\frac{\text { Ciencias naturales y exactas }}{\text { FIsica y matemáticas }}$ & $\begin{array}{r}.127 \\
66 \\
61\end{array}$ & $\begin{array}{r}153 . \\
77 \\
76\end{array}$ & $\begin{array}{r}163 \\
86 \\
77\end{array}$ & $\begin{array}{l}211 \\
117 \\
94\end{array}$ & $\begin{array}{l}279 \\
177 \\
102\end{array}$ & $\begin{array}{l}314 \\
.175 \\
.139\end{array}$ & $\begin{array}{l}376 \\
230 \\
146\end{array}$ & $\begin{array}{l}514 \\
315 \\
199\end{array}$ & $\begin{array}{l}1.52 \\
0.79 \\
0.73\end{array}$ & $\begin{array}{l}2.77 \\
1.70 \\
1.07\end{array}$ \\
\hline 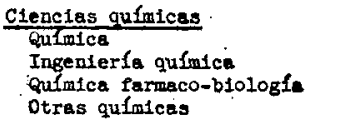 & $\begin{array}{r}829 \\
1300 \\
397 \\
254 \\
48\end{array}$ & $\begin{array}{r}895 \\
141 \\
430 \\
271 \\
53\end{array}$ & $\begin{array}{r}1055 \\
155 \\
570 \\
273 \\
57\end{array}$ & $\begin{array}{r}993 \\
164 \\
562 \\
213 \\
54\end{array}$ & $\begin{array}{r}953 \\
115 \\
534 \\
245 \\
59\end{array}$ & $\begin{array}{r}1022 \\
119 \\
591 \\
253 \\
59\end{array}$ & $\begin{array}{r}1072 \\
136 \\
586 \\
286 \\
63\end{array}$ & $\begin{array}{r}120 \\
117 \\
622 \\
312 \\
69\end{array}$ & $\begin{array}{l}9.87 \\
1.55 \\
4.73 \\
3.02 \\
0.57\end{array}$ & $\begin{array}{l}6.03 \\
0.63 \\
3.35 \\
1.68 \\
0.37\end{array}$ \\
\hline 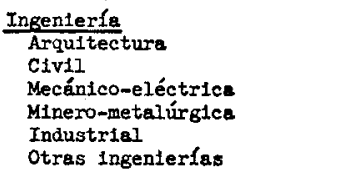 & $\begin{array}{r}2421 \\
580 \\
771 \\
674 \\
51 \\
22 \\
323\end{array}$ & $\begin{array}{r}2705 \\
632 \\
900 \\
763 \\
51 \\
28 \\
331\end{array}$ & $\begin{array}{r}3075 \\
654 \\
2011 \\
903 \\
39 \\
40 \\
428\end{array}$ & $\begin{array}{r}3506 \\
1.007 \\
991 \\
972 \\
28 \\
.51 \\
457\end{array}$ & $\begin{array}{rl}3 & 548 \\
1 & 087 \\
919 \\
1023 \\
27 \\
82 \\
410\end{array}$ & $\begin{array}{r}3706 \\
999 \\
936 \\
1102 \\
26 \\
239 \\
404\end{array}$ & $\begin{array}{rl}4 & 316 \\
1 & 060 \\
1 & 095 \\
1 & 457 \\
53 \\
304 \\
347\end{array}$ & $\begin{array}{rl}4 & 430 \\
975 \\
1160 \\
1 & 576 \\
62 \\
337 \\
320\end{array}$ & $\begin{array}{l}28.82 \\
6.90 \\
9.18 \\
8.02 \\
0.61 \\
0.26 \\
3.85\end{array}$ & $\begin{array}{l}23.88 \\
5.27 \\
6.25 \\
8.49 \\
0.33 \\
1.82 \\
1.72\end{array}$ \\
\hline$\frac{\text { Grupo agropecuerio }}{\text { Agronomi }}$ & $\begin{array}{r}183 \\
101 \\
82\end{array}$ & $\begin{array}{l}227 \\
112 \\
115\end{array}$ & $\begin{array}{l}284 \\
129 \\
155\end{array}$ & $\begin{array}{l}321 \\
151 \\
170\end{array}$ & $\begin{array}{l}405 \\
219 \\
186\end{array}$ & $\begin{array}{l}368 \\
164 \\
224 .\end{array}$ & $\begin{array}{l}523 \\
227 \\
296\end{array}$ & $\begin{array}{l}608 \\
292 \\
316\end{array}$ & $\begin{array}{l}2.18 \\
1.20 \\
0.98\end{array}$ & $\begin{array}{l}3.28 \\
1.57 \\
1.71\end{array}$ \\
\hline 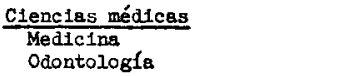 & $\begin{array}{l}1593 \\
1387 \\
206\end{array}$ & $\begin{array}{l}1623 \\
1400 \\
223\end{array}$ & $\begin{array}{l}2735 \\
1459 \\
276\end{array}$ & $\begin{array}{ll}1 & 768 \\
1 & 444 \\
324\end{array}$ & $\begin{array}{l}1 \quad 973 \\
1635 \\
338\end{array}$ & $\begin{array}{l}2153 \\
1751 \\
402\end{array}$ & $\begin{array}{l}2623 \\
2140 \\
.483\end{array}$ & $\begin{array}{l}2729 \\
2189 \\
540\end{array}$ & $\begin{array}{r}18.96 \\
16.51 \\
2.45\end{array}$ & $\begin{array}{r}14.77 \\
11.80 \\
2.91\end{array}$ \\
\hline Humanidades & 776 & 939 & 1223 & 1420 & 1780 & 2504 & 2841 & 2821 & 9.24 & 15.21 \\
\hline Otras & 27 & 18 & 20 & 25 & 50 & 45 & 68 & 95 & 0.20 & 0.51 \\
\hline
\end{tabular}

Fuente: Véase la nota introductoria de este apén dice en cuanto a las fuentes, el concepto de "egresados", las limitaciones de los datos y el contenido de cada uno de los rubros de las

Los datos de 1963 a 1967 son observados y los de 1960-1962 son estimaciones. 
Cuadro A-6

México: Egresados de las instituciones de educación superior, Distrito Federal y resto del país, POR RAMA PROFESIONAL, 1960-1967

\begin{tabular}{|c|c|c|c|c|c|c|c|c|c|c|}
\hline Ramas profestonales & 1960 & 1961 & 1962 & 1963 & 1964 & 1965 & 1966 & 2967 & $\frac{\text { D1stribución }}{1960}$ & $\frac{\text { porcentusel }}{1967}$ \\
\hline Total nacional & 8400 & 9320 & 10795 & 11743 & 13109 & 15241 & 17977 & 18553 & 100.0 & 100.0 \\
\hline $\begin{array}{l}\text { D1strito Pederal } \\
\text { Clencias administrativas } \\
\text { Cienclas naturales y exactas } \\
\text { Cleneias quf́licas } \\
\text { Ingenierias } \\
\text { Grupo agropecuario } \\
\text { Clencias médicas } \\
\text { Humanidades } \\
\text { Otras }\end{array}$ & $\begin{array}{r}5720 \\
1603 \\
98 \\
630 \\
172 \\
778 \\
1041 \\
541 \\
17\end{array}$ & $\begin{array}{r}6262 \\
1819 \\
119 \\
669 \\
1912 \\
108 \\
1038 \\
579 \\
18\end{array}$ & $\begin{array}{r}7275 \\
2171 \\
127 \\
793 \\
2187 \\
145 \\
1099 \\
733 \\
20\end{array}$ & $\begin{array}{r}7606 \\
2221 \\
164 \\
674 \\
2470 \\
153 \\
1 \quad 149 \\
750 \\
25\end{array}$ & $\begin{array}{rl}8 & 171 \\
2 & 630 \\
237 \\
626 \\
2 \quad 373 \\
159 \\
156 \\
1540 \\
50\end{array}$ & $\begin{array}{rr}9 & 162 \\
3 & 141 \\
264 \\
649 \\
2 & 176 \\
187 \\
1 & 301 \\
1 & 403 \\
& 41\end{array}$ & $\begin{array}{rl}10 & 593 \\
3 & 677 \\
317 \\
612 \\
2444 \\
214 \\
1536 \\
1729 \\
64\end{array}$ & $\begin{array}{rl}10 & 458 \\
3 & 389 \\
444 \\
648 \\
2505 \\
225 \\
253 \\
1637 \\
1520 \\
90\end{array}$ & $\begin{array}{r}68.1 \\
19.1 \\
1.2 \\
7.5 \\
20.4 \\
0.9 \\
12.4 \\
6.4 \\
0.2\end{array}$ & $\begin{array}{r}56.4 \\
18.3 \\
2.4 \\
3.5 \\
13.5 \\
1.2 \\
8.8 \\
8.2 \\
0.5\end{array}$ \\
\hline $\begin{array}{l}\text { Resto del país } \\
\text { Ciencias administrativas } \\
\text { Clencias naturiles y exactas } \\
\text { Clencias químicas } \\
\text { Ingenierias } \\
\text { Grupo agropecuario } \\
\text { C1eneias médicas } \\
\text { Hunanidades } \\
\text { Otras }\end{array}$ & $\begin{array}{r}2680 \\
851 \\
29 \\
199 \\
709 \\
105 \\
552 \\
235 \\
-\end{array}$ & $\begin{array}{r}3058 \\
941 \\
34 \\
226 \\
793 \\
119 \\
585 \\
360 \\
-\end{array}$ & $\begin{array}{r}3520 \\
1079 \\
36 \\
262 \\
888 \\
139 \\
636 \\
480 \\
-\end{array}$ & $\begin{array}{r}4137 \\
1278 \\
47 \\
319 \\
1036 \\
168 \\
619 \\
670 \\
-\end{array}$ & $\begin{array}{r}4938 \\
1491 \\
42 \\
327 \\
1175 \\
246 \\
817 \\
840 . \\
-\end{array}$ & $\begin{array}{r}6079 \\
1968 \\
50 \\
373 \\
1530 \\
201 \\
852 \\
1 \quad 101 \\
4\end{array}$ & $\begin{array}{r}7384 \\
2482 \\
59 \\
459 \\
1872 \\
309 \\
1087 \\
1112 \\
4\end{array}$ & $\begin{array}{r}8095 \\
2847 \\
70 \\
472 \\
1925 \\
383 \\
1092 \\
1301 \\
5\end{array}$ & $\begin{array}{r}31.9 \\
10.1 \\
0.3 \\
2.4 \\
8.4 \\
1.3 \\
6.6 \\
2.8 \\
0.0\end{array}$ & $\begin{array}{r}43.6 \\
15.3 \\
0.4 \\
2.5 \\
10.4 \\
2.1 \\
5.9 \\
7.0 \\
0.0\end{array}$ \\
\hline
\end{tabular}

Fuente: Véase la nota del cuadro A-5. 